\title{
Impacto de choques de política monetária sobre a oferta de crédito regional: Uma análise econométrica a partir da metodologia VAR para o Brasil nos anos $2000^{*}$
}

\author{
Leonardo Dondoni Dutra ${ }^{\dagger}$ \\ Carmem Aparecida do Valle Feijó ${ }^{\ddagger}$ \\ Julio Cesar Albuquerque Bastos ${ }^{\S}$
}

\begin{abstract}
Resumo
O objetivo deste trabalho é investigar empiricamente o impacto da política monetária na oferta de crédito nas regiões brasileiras, partindo da hipótese de que este impacto será diferenciado ao nível das regiões brasileiras. Desta forma, utilizando uma base de dados inédita a partir das Estatísticas Bancárias Municipais do Banco Central do Brasil para os anos 2000-2012, este trabalho busca investigar se o comportamento diferenciado por parte das firmas bancárias a níveis regionais mapeadas pela preferência pela liquidez bancária e pelo nível de incerteza, tomado como proxy das provisões de operações de crédito, pode interferir na oferta de crédito em suas diferentes maturidades, ou seja, em seus diferentes prazos de concessão. Nesse contexto, o estudo conclui que a política monetária causa impactos diferenciados na oferta de crédito em suas diferentes maturidades, ao nível das regiões brasileiras, ocasionados pela atuação diferenciada do comportamento de gestão bancária. Este comportamento diferenciado de gestão bancária ao nível de regiões compromete a possibilidade desse setor em se tornar o elemento proeminente do processo de indução ao crescimento econômico e de redução das desigualdades regionais.
\end{abstract}

Palavras-chave: banco regional, preferência pela liquidez, crédito regional.

\begin{abstract}
The aim of this paper is to investigate empirically the impact of monetary policy on the credit supply in the Brazilian regions, based on the hypothesis that this impact will be differentiated at the level of the Brazilian regions. Thus, using an inedited database based on the Municipal Banking Statistics of the Central Bank of Brazil for the years 2000-2012, this paper seeks to investigate whether the differentiated behavior of banking firms at regional levels mapped by liquidity of preference and by the level of uncertainty, taken as a proxy for provisions of credit operations, may interfere in the credit supply in its different maturities of concession. In this context, this study concludes that the monetary policy causes differential impacts on the credit supply in its different maturities, at the level of the Brazilian regions, caused by the differentiated behavior performance of the banking management. This differentiated behavior of bank management at the level of the regions compromises the possibility of this sector to become the prominent element of the process of induction to economic growth and reduction of regional inequalities.
\end{abstract}

Keywords: regional banking, liquidity preference, regional credit.

JEL Classification: E44, 016.

\footnotetext{
* Os autores agradecem os profícuos comentários dos pareceristas anônimos, isentando-os de quaisquer falhas ou omissões que ainda persistam.

${ }^{\dagger}$ Economista da Eletrobras; Doutorando em Economia - Universidade Federal Fluminense.

${ }^{\ddagger}$ Professora Titular da UFF, bolsista de produtividade de CNPq.

$\S$ Professor Adjunto da UFF.
} 


\section{Introdução}

O interesse acadêmico pelo desenvolvimento financeiro regional ganhou fôlego com as mudanças no sistema financeiro internacional a partir dos anos 1970 . No entanto, até hoje, grande parte da literatura sobre desenvolvimento regional desconsidera os efeitos de fatores monetários e financeiros para explicar o crescimento desigual entre as regiões. Predominam explicações que consideram aspectos reais, como a disponibilidade de recursos, a mobilidade de fatores, os padrões de produção e as condições de mercado.

A literatura pós-Keynesiana, por sua vez, baseada em Keynes (1971) e Minsky (1986) e aprofundado por diversos autores como Davidson (1978, 1986), Kregel (1985), Chick (1986), , Carvalho (1993), Paula (1998) e muitos outros, assume que bancos, em particular, desempenham papel crucial na determinação do nível de renda e emprego em economias monetárias sob a hipótese da não neutralidade da moeda no curto e longo período.

No âmbito da literatura sobre desenvolvimento regional, dada a institucionalidade do sistema financeiro nacional, esta corrente teórica assume que a disponibilidade de crédito por região depende da preferência pela liquidez dos bancos que consideram as especificidades de cada local (Chick e Dow, 1988; Dow, 1990 e 1993, Amado, 1997, Rodrigues-Fuentes, 1998, Crocco, 2010, dentre outros). Ou seja, sob esta perspectiva teórica, a disponibilidade de crédito em diferentes regiões é resultado da preferência pela liquidez dos bancos a nível regional, cuja estratégia de gerenciamento de recursos é definida a nível nacional.

Em linhas gerais, a firma bancária, atuando em diversas regiões com graus diferenciados de desenvolvimento econômico busca manter uma razão entre liquidez e rentabilidade de sua carteira de ativos percebida como desejável em cada região. Sob a hipótese da não neutralidade da moeda, esta proporção percebida como desejável é formada por expectativas em relação ao desempenho futuro da economia e ao ambiente econômico regional.

Uma implicação importante do comportamento dos bancos em direção à preferência pela liquidez é que seu efeito é maior para as regiões menos desenvolvidas e mais necessitadas de recursos para estimular seu crescimento econômico (Rodrigues-Fuentes, 1998 e Rodrigues-Fuentes e Dow, 2003). No caso brasileiro, esse comportamento diferenciado pode ser observado à luz do processo de consolidação do sistema bancário, que ratificou a concentração deste sistema ${ }^{1}$ na região Sudeste do país, a de maior desenvolvimento econômico. O processo de concentração bancária foi reforçado nos anos 1990 a partir do intenso processo de internacionalização desse sistema por intermédio dos movimentos de fusões e aquisições de bancos.

Nesse aspecto, contribuições empíricas como a de Alexandre et al. (2005) e Correa (2006), por exemplo, mostram que a alocação das agências bancárias no território nacional guarda estreita correlação com a distribuição regional da população e com o dinamismo de crescimento do PIB local.Ao se considerar uma estratégia diferenciada por parte do sistema bancário em distribuir suas agências no território, a disponibilidade de moeda e os padrões regionais de criação de crédito variarão de uma região para outra. De fato, Dutra e Bastos

\footnotetext{
${ }^{1}$ O processo de consolidação bancária no Brasil, mesmo que tenha se acelerado em meados da década de 1990, teve início em 1988, quando o Conselho Monetário Nacional criou a figura do banco múltiplo. Todavia, após a estabilização em 1994 e a desregulamentação do setor, o processo de consolidação foi impulsionado, podendo ser acrescentados como fatores motivadores adicionais o processo de estabilização de preços, o programa de privatizações dos bancos estaduais e a adesão aos acordos da Basiléia. A concentração bancária brasileira pode ser dividida em dois movimentos que ocorrem simultaneamente: i) concentração geográfica das agências bancárias e; ii) forte movimento de fusões, aquisições e liquidações (ver, por exemplo, Carvalho e Paula, 2014.).
} 
(2016), analisando o comportamento dos bancos por regiões nos anos 2000, concluem que as instituições bancárias localizadas em regiões menos desenvolvidas obtêm maior rentabilidade via instrumentos de crédito com baixa maturidade.

Partindo da hipótese de que a gestão dos ativos por parte dos bancos nas regiões é diferenciado, o objetivo deste trabalho é investigar o impacto de choques de política monetária na oferta de crédito nas regiões brasileiras. Tal impacto pode acentuar as desigualdades na geração de renda e emprego. ${ }^{2}$ Para explorar esta hipótese empiricamente, este trabalho irá caracterizar inicialmente as diferenças de reação da firma bancária a nível regional a um choque positivo de juros considerando duas variáveis de comportamento: a preferência pela liquidez e a provisão de operações de crédito como uma proxy para a incerteza. A análise conjunta destas duas variáveis de comportamento da firma bancária sob a ótica regional deve fornecer elementos para caracterizar o comportamento da oferta de crédito regional, considerando diferentes maturidades, etapa seguinte do exercício econométrico.

Desta forma, este trabalho testará a hipótese de que a oferta de crédito regional é resultado dos comportamentos diferenciados da firma bancária (ao buscar equilibrar seu portfólio considerando a preferência pela liquidez na sua carteira de ativos frente à percepção de aumento da incerteza quanto ao ambiente econômico e a rentabilidade esperada. Dado que o comportamento da firma bancária é diferenciado por região, o impacto de choques de política monetária a nível regional também é diferenciado, com implicações sobre a oferta de crédito comprometendo a possibilidade do setor bancário em se tornar o elemento proeminente no processo de indução ao crescimento econômico das regiões.

O presente artigo é composto de cinco seções, incluindo esta introdução. A segunda seção discute a relação entre oferta de crédito e a política monetária na teoria pósKeynesiana. A seção 3 apresenta um levantamento de estudos recentes que retratam o tema. A seção 4 apresenta a metodologia do modelo econométrico e os resultados obtidos. $\mathrm{Na}$ quinta seção encontram-se as considerações finais.

\section{Política monetária e oferta de crédito regional}

A firma bancária, enquanto captadora de depósitos junto ao público, ao ofertar crédito cria moeda. Na tradição keynesiana a moeda permeia todo o ambiente econômico por intermédio de sua endogeneidade, e por ser assumida não neutra, afeta o nível de produção, renda e, consequentemente, o volume de emprego. A não neutralidade da moeda decorre da hipótese de que decisões são tomadas sob incerteza não-probabilística (distinta de risco) e, portanto, comportamentos racionais são pautados pela preferência pela liquidez.

Nesse contexto teórico, mesmo que a autoridade monetária injete moeda na economia, nada garante que os volumes de emprego e renda gerados sejam os de equilíbrio de pleno emprego, pois, uma parte da oferta de moeda depende do estado de preferência

\footnotetext{
${ }^{2}$ Dentre os canais de transmissão da política monetária pelo menos juros e crédito se relacionam intrinsecamente com o sistema bancário. Para o Brasil, esses dois canais parecem não funcionar em sua completude conforme apontam Modenesi e Modenesi (2012). Segundo estes autores assume-se que existem falhas no mecanismo de transmissão da política monetária que podem ser atribuídas ao baixo grau de penetração financeira, ampla participação do sistema bancário em prover empréstimos de curto prazo e elevada preferência pela liquidez reduzindo a participação do sistema bancário em prover recursos ao financiamento do investimento. De forma complementar, em estudo recente de Evangelista e Sbardellati (2016), as autoras concluem que o efeito da política monetária, via canal de oferta de crédito é assimétrico, afetando mais o produto onde a assimetria de informação tem maior peso (no caso do estudo, o crédito a pessoa física).Ambos os estudos sugerem que a política monetária como praticada no Brasil no período de nosso estudo acentua desigualdades econômicas.
} 
pela liquidez dos bancos. Dito de outra forma, a atuação dos bancos em economias modernas não é vista como um mero intermediário entre agentes econômicos, pois suas escolhas de alocação de recursos, mais do que amplificar os impactos de política monetária, têm efeito duradouro sobre o desenvolvimento da economia. ${ }^{3}$ Dessa forma, economias monetárias são propensas a gerar desemprego, e tanto maior será esta propensão quanto maior for a preferência pela liquidez de bancos implicando maior racionamento do crédito (FEIJÓ et al., 2012).

A postura dos bancos em relação à oferta de crédito depende do estado das expectativas em relação às oportunidades de ganhos futuros. Assume-se, portanto, que bancos possuem discricionariedade na concessão do crédito e na administração de seus portfólios se defrontam com o trade-off entre liquidez e rentabilidade. A preferência pela liquidez expressa a precaução dos bancos aos resultados a serem alcançados na aplicação de seus ativos. Por outro lado, dado o desenvolvimento do sistema financeiro, bancos podem satisfazer suas preferências por liquidez através da substituição de ativos de risco (crédito bancário) para outros tipos de ativo com maior liquidez.

Dessa forma, dada esta possibilidade, a atuação dos bancos na oferta de crédito em regiões com diferentes graus de desenvolvimento também será influenciada pelas oportunidades de aplicação de seus ativos. Desse modo, o comportamento diferenciado em direção a ativos mais líquidos que não o crédito pode ser responsável pela manutenção e mesmo pela ampliação das diferenças de renda regionais (Amado, 1997; Chick, 1986; Dow,1990; Rodriguez-Fuentes, 1996; dentre outros).

A literatura Pós keynesiana mostra que o sistema financeiro regional, juntamente com condicionantes do lado real da economia, podem promover e perpetuar padrões de desenvolvimento regional desiguais. Isto porque assume-se que preferência pela liquidez dos bancos é maior em regiões economicamente menos desenvolvidas, e que bancos localizados nestas áreas perdem mais reservas do que os bancos que estão localizados nas áreas mais dinâmicas. Por isso, emprestam menos e a uma taxa de juros mais elevada contribuindo para tornar a economia local menos dinâmica, reforçando o ciclo de uma maior preferência pela liquidez e baixo crescimento. Uma vez assumido que a atuação dos bancos em regiões menos desenvolvidas reforça as desigualdades de oportunidades de desenvolvimento, cabe indagar como a política monetária afeta o desenvolvimento regional=

Neste sentido, a visão Pós keynesiana advoga que a política monetária deveria levar em conta o grau de desenvolvimento do sistema bancário nas distintas regiões, tendo em vista que a transmissão da política monetária através do canal de oferta de crédito afeta não só da preferência pela liquidez dos bancos, mas pode implicar também num vazamento de depósitos para regiões mais desenvolvidas. Isto pode ocorrer porque a demanda por alocação de recursos em ativos mais líquidos pode não ser atendida localmente, pois estes recursos podem não estar disponíveis localmente (ver Dow $(1982,1990,1993)$.

Em suma, uma política monetária contracionista leva a que bancos ao mesmo tempo que aumentam sua preferência pela liquidez na região menos desenvolvida, busquem

\footnotetext{
${ }^{3} \mathrm{O}$ único mecanismo de transmissão de política monetária, na literatura mainstream, através do qual o crédito pode afetar o crescimento é através do chamado canal de crédito. Esta literatura explora se a informação imperfeita e outros atritos "nos mercados de crédito podem ajudar a explicar a potência da política monetária" (Bernanke e Gertler 1995, p. 44). Ou seja, não se assume qualquer efeito dos fluxos de crédito sobre a economia real. De acordo com os autores, " não é sensato pensar o canal de crédito como uma alternativa diferente ao tradicional mecanismo de transmissão monetária, mas sim como um conjunto de fatores que amplificam e propagam os efeitos das taxas de juros convencionais." (Bernanke e Gertler 1995: 44).
} 
rentabilidade com segurança direcionando aplicações em ativos mais líquidos nas regiões mais desenvolvidas. Ou seja, quanto maior a preferência por ativos mais líquidos maior será o racionamento do crédito nas regiões menos desenvolvidas que ofertam menores oportunidades de manutenção da razão liquidez e rentabilidade. $O$ direcionamento para ativos mais líquidos resultando no vazamento de depósitos atende a uma estratégia defensiva dos bancos em regiões menos desenvolvidas, ou seja, a uma estratégia de redução da exposição ao risco na concessão de crédito.

\section{Estudos sobre impactos regionais de política monetária}

A literatura sobre impactos de política monetária a nível regional para o Brasil, em quase sua totalidade, aborda somente os aspectos estruturais na incidência da política monetária, não discutindo o comportamento da firma bancária nas diferentes regiões. Esta limitação deve-se, sobretudo, à dificuldade de se obter dados regionais com a temporalidade e um conjunto de informações que permitem trabalhar com graus de liberdade suficientes para estimações econométricas.

Um dos primeiros trabalhos nacionais deve-se a Fonseca e Vasconcelos (2002). Os autores, analisando o canal de crédito no período de julho/1994 a dezembro/2000, mediram a influência da taxa Selic sobre o crédito bancário fazendo uma comparação com o trabalho de Carlino e Defina (1997). Concluíram que quanto ao canal de crédito as regiões Norte, Nordeste e Centro-Oeste seriam as mais afetadas dado um choque de política monetária devido à maior proporção de pequenas e médias empresas no total de emprego gerado na produção industrial e à maior restrição da atuação dos bancos na concessão de crédito.

Rocha e Nakane (2007) analisaram o canal de transmissão da política monetária de janeiro de 1995 a novembro de 2003 para alguns estados brasileiros utilizando a metodologia de fatores dinâmicos. Constataram que o choque monetário produziu respostas assimétricas no nível de atividade dos estados e regiões do país. Bahia e Paraná, por exemplo, foram os estados mais prejudicados em termos de produto; enquanto São Paulo, Pernambuco e Minas Gerais foram menos afetados. Os autores concluíram que as assimetrias observadas podem ser explicadas pela existência de um canal de crédito mais ativo entre os estados mais afetados pela política monetária, que contam com uma estrutura bancária mais restrita o que provocaria distorções no fornecimento de crédito, além de uma concentração de firmas potencialmente mais sujeitas à problemas de informação.

Na mesma linha, o trabalho de Bertanha e Haddad (2008) analisou os impactos da taxa básica de juros (SELIC) para o nível de atividade dos estados brasileiros, a partir do uso de séries temporais e econometria espacial. De maneira geral, observaram que os estados do Nordeste tiveram o volume de emprego mais afetado em decorrência do aumento dos juros. Os autores concluem que aspectos "estruturais", ou seja, a dinâmica setorial das regiões explica diferentes impactos dos choques monetários nas regiões.

Rocha et al. (2011) trabalharam a hipótese das reações assimétricas a choques da política monetária que os estados brasileiros enfrentam. Sugeriram que a intensidade da variação do produto estadual é relacionada diretamente às variáveis de composição industrial, grau de abertura e volume de crédito. Segundo apontaram, estados com maior volume de depósitos bancários responderam mais intensamente a choques monetários oferecendo suporte ao canal de crédito.

A nível internacional proliferaram estudos abordando as assimetrias verificadas na atividade econômica dos países que podem ser ocasionadas por choques monetários nacionais, quer em respectivos setores que compõem o produto/renda quer em regiões 
específicas que compõem uma economia nacional (ver Carlino e Defina, 1997; Cecchetti, 1999; Cecchetti e Krause, 2001; Favero, Giavazi e Flabbi, 1999, Svensson, 2012).

O trabalho de Rodriguez-Fuentes e Padron-Marrero (2008) é motivado pelo interesse do entendimento dos ajustes provocados pela perda da soberania monetária de países da União Européia quando aceitaram sua conversão ao Euro. Os autores constataram a importância de se considerar tanto a estrutura produtiva denominada de "estructural effects" bem como por "behavioral effects", ou seja as diferentes estruturas financeiras e seus estágios de desenvolvimento bancário influenciando as distintas preferências pela liquidez.

Estudos nacionais que retratam o comportamento diferenciado da firma bancária utilizando variáveis monetárias e financeiras vêem ganhando notoriedade acadêmica. Feijó et al. (2012) apresentaram um estudo empírico sobre o comportamento do crédito bancário para a pessoa jurídica a nível regional no período 2000-2008. Com base nas estatísticas do banco de dados - ESTBAN, estimaram as variáveis de um modelo econométrico desenvolvido para explicar os determinantes do crédito às empresas nas diferentes regiões brasileiras. Apoiado na literatura Pós keynesiana, os autores confirmaram a importância da preferência pela liquidez da firma bancária para explicar a oferta de crédito às empresas, assim como a importância da concentração do sistema bancário para reforçar as desigualdades regionais

Destaca-se também o estudo de Nogueira et al. (2015) que discute se o sistema financeiro bancário possui uma estratégia diferenciada no espaço por intermédio de comportamentos diferenciados da firma bancária. Concluíram que a racionalidade das decisões bancárias está relacionada com a centralidade das cidades, ratificando a tese de Crocco (2010, p.151). O caráter altamente concentrado do sistema bancário brasileiro, segundo os autores deve ser realçado nas estratégias de comportamento diferenciado das firmas bancárias na direção da compatibilização entre rentabilidade e liquidez reforçando a tese de Carvalho (1993).

Por sua vez, Dutra et al. (2015) estudaram o comportamento do crédito bancário para pessoa jurídica em termos regionais para o período 2000-2011. O estudo apontou para a existência de um paradoxo financeiro da eficiência social, ou seja, se o sistema financeiro é o ponto de partida do processo de ratificação das demandas efetivas então um redirecionamento dos bancos a posições mais líquidas, ou melhor, a um aumento da preferência pela liquidez, acabará por causar uma ruptura nos processos decisórios dos agentes. Essa maior preferência pela liquidez acaba por não ratificar o processo de contratações de meios de produção e alocação de renda que deveria ser iniciado pela disponibilidade de crédito a pessoa jurídica.

De forma complementar, Dutra e Bastos (2016) contribuíram com a ratificação de evidências de fortes indicações de estratégias diferenciadas de gestão do ativo bancário a nível regional, no período 2000-2012, que reforçariam as desigualdades regionais existentes. Os autores confirmaram, o que é assumido na teoria bancária Pós keynesiana, que a variável mais importante no processo decisório das firmas bancárias é a preferência pela liquidez ancorada pela sua percepção quanto a um futuro incerto. Dito de outra forma, a preferência pela liquidez é o fio condutor da orientação da firma bancária na alocação de seus recursos com base nas avaliações de suas percepções quanto aos retornos esperados.

\section{Análise empírica}

O método de estimação econométrico utilizado é o de vetores auto-regressivos. Já bastante difundido na literatura, o método VAR é usado para previsão de séries temporais interrelacionadas e analisar a dinâmica do impacto de um distúrbio aleatório sobre o sistema de variáveis. O VAR é um modelo estrutural por se tratar de variáveis endógenas no sistema como 
função do valor defasado dos todas as variáveis endógenas. A representação formal do modelo VAR é como segue:

$$
y_{t}=A_{1} y_{t-1}+\ldots+A_{p} y_{t-p}+B x_{t}+u_{t}
$$

Onde $Y_{t}$ é o vetor de variáveis endógenas; $x_{t}$ é o vetor de variáveis exógenas; A e B são as matrizes dos coeficientes estimados e ut é o vetor de inovações que deve ser contemporaneamente correlacionado, mas não correlacionado com todas variáveis dos valores defasados e com as variáveis exógenas.

A opção do estudo de impulso resposta é a dos impulsos generalizados. Como apontado por Lütkepohl (1991), o método aplica a suposição de ortogonalidade e então o resultado pode depender sobre a ordem das variáveis no VAR. Por sua vez, Koop et al. (1996) e Pesaran e Shin (1998) desenvolveram a ideia de uma função resposta de impulsos generalizados como uma maneira de eliminar o problema da ordenação das variáveis no $\operatorname{VAR}^{4}$.

\subsection{Apresentação da base dados e descrição dos modelos econométricos}

A base de dados utilizada nas estimações foi extraída da estatística ESTBAN, do Banco Central do Brasil, que disponibiliza as contas contábeis para os municípios brasileiros que possuem ao menos uma agência bancária. Os valores para estimação foram construídos a partir da agregação dos dados dos municípios aos estados e em seguida às regiões brasileiras para o período de janeiro de 2003 a dezembro de $2012^{5}$, dados mensais.

Foram desenvolvidos dois modelos. No primeiro modelo são considerados os efeitos da política monetária sobre variáveis de comportamento da firma bancária em cada região. Para avaliar os comportamentos diferenciados da firma bancária foram definidas as variáveis:

1. preferência pela liquidez bancária.

Liquidity_preference

2. provisão para créditos duvidosos, uma proxy para incerteza Uncertainity

A variável preferência pela liquidez, utilizada por Dutra et al. $(2015)^{6}$, foi a variável mais importante em termos de impacto na oferta de crédito para todas as regiões do país. A fim de captar a incerteza na condução da atividade bancária foi utilizada como proxy as provisões para operações de crédito ${ }^{7}$. Os bancos têm que classificar as operações de crédito em ordem decrescente de risco, ${ }^{8}$ o que deve ser efetuado com base em critérios consistentes

\footnotetext{
${ }^{4}$ Há duas vantagens potenciais com este método (Ewing, 2003): (i) a função resposta dos impulsos generalizados provê mais robustez aos resultados do que o método ortogonalizado, e; (ii) devido ao fato que ortogonalidade não é imposta, a função resposta dos impulsos generalizados permite uma interpretação significativa da resposta do impacto inicial de cada variável à choques de outras variáveis.

${ }^{5}$ Vale destacar que o Distrito Federal foi excluído da região Centro-Oeste, porque Brasília impacta os dados coletados por ser a sede dos dois maiores bancos públicos do país -Banco do Brasil e Caixa Econômica, além de todas as operações bancárias relacionadas à administração federal estarem concentradas nesta cidade. Estes dois fatores interferem nos balancetes das agências bancárias ali localizadas, fazendo com que os indicadores desta região sejam influenciados não apenas por fatores econômicos, mas também pelo fator político.

${ }^{6}$ Conforme Dutra et al. (2015) é definido como a razão entre o depósito à vista do setor privado (conta 410) e do governo (conta 400) pelas operações de crédito total (conta 160) das regiões. Ver também Freitas e Lamonica (2015).

${ }^{7}$ A variável Provisões para operações de crédito - conta ESTBAN 174 - foi utilizada por Dutra e Bastos (2016) como uma proxy para a incerteza.

8 A cclassificação das operações de crédito são dadas pela Resolução no 2682; art 2ㅇ; § I;l, em ordem crescente de risco, nos seguintes níveis: nível AA; nível A; nível B; nível C; nível D; nível E; nível F; nível G e nível $\mathrm{H}$.
} 
e verificáveis, amparados em informações que contemplem uma série de avaliações dos devedores e garantidores tais como: situação econômico-financeira; grau de endividamento; capacidade de geração de caixa; pontualidade e atrasos nos pagamentos e também o setor de atividade econômica.

As provisões para operações de crédito devem ser constituídas mensalmente de acordo com as respectivas margens de constituição dos valores para se fazer face as perdas prováveis na realização dos créditos. Dentre a classificação dos níveis de risco inseridos pela regulamentação ${ }^{9}$ as participações dos montantes devem ser alocadas a partir de $0,5 \%$ sobre o valor das operações classificadas no menor nível de risco até atingir o montante de $100 \%$ do valor da operação de crédito de acordo com o mais alto nível de risco cujo atraso de pagamentos for superior a 180 dias. Nesse contexto, espera-se que um choque positivo na taxa básica de juros leve a um aumento dos custos de carregamento dos créditos e financiamentos, impactando em um aumento da inadimplência dos detentores de créditos e financiamentos.

No segundo modelo investiga-se o canal de transmissão de política monetária através da oferta de crédito (canal do crédito) a nível regional. São consideradas três modalidades de crédito: de curto prazo; de longo prazo e de financiamento agrícola. Para a mensuração do impacto da política monetária via canal de crédito regional foram estruturadas as variáveis ${ }^{10}$ :

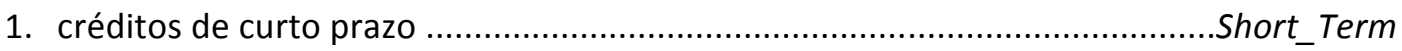

2. financiamentos destinados à produção.........................................................Produc financing

3. financiamentos à agricultura. Rural financing

As variáveis utilizadas para medir os diferentes impactos sobre as diferentes maturidades de crédito como os créditos de curto prazo, financiamentos destinados à produção e agricultura foram utilizados por Dutra e Bastos (2016). Para gerenciar os impulsos do sistema VAR utilizou-se a taxa de juros de curto prazo, Selic (Interest), disponibilizada pelo Banco Central do Brasil. Todas as variáveis dos dois modelos foram utilizadas em termos de suas variações percentuais.

\subsection{Resultados da estimação econométrica}

Esta seção apresenta os resultados dos dois modelos utilizando-se a metodologia VAR função impulso-resposta generalizados, aplicados a cada uma das cinco regiões geográficas brasileiras. Segundo Sims (1980) e Sims et al. (1990), não existem maiores problemas em se trabalhar com variáveis estacionárias ou não estacionárias em um modelo VAR, uma vez que é uma metodologia que está interessada nas inter-relações entre as variáveis. Mesmo assim, verificamos se as séries têm raiz unitária. Para tanto, foram realizados os testes de raiz unitária Dikey-Fuller aumentado (ADF), Phillips-Perron (PP) e Kwiatkowski-Phillips-Schmidt-Shin (KPSS). Os resultados revelam que todas as variáveis são estacionárias. Os testes para cada região são apresentados no Apêndice $C$, Quadros de 1 a 5 . Pode-se observar que todas as variáveis foram estacionárias em pelo menos dois testes, sendo por unanimidade para a maioria. Apenas a variável var_liquidity_preference não apresentou unanimidade para estacionariedade, em três casos: na região Nordeste para o teste KPSS; região Sul para o teste ADF; e região Norte para o teste KPSS.

Além disso, promoveu-se os testes de escolha da ordem de defasagens do VAR nos modelos estimados (comportamento dos bancos e oferta de crédito), assim como os testes de

9 Resolução Banco Central do Brasil no 2682; art 6o; I;V;II.

${ }^{10}$ No quadro 2, apêndice $A$, estão apresentadas as descrições das variáveis. No quadro 3, apêndice B, estão as descrições das agregações das variáveis e contas utilizadas da ESTBAN. 
estabilidade do VAR. Os resultados encontram-se no Apêndice $D$, gráficos de 6 a 15 e figuras de 1 a 10. A ordem do VAR foi escolhida pela maioria entre os cinco critérios utilizados, a saber: Sequential modified LR test statistic (each test at $5 \%$ level) (LR); Final prediction error (FPE); Akaike information criterion (AIC); Schwarz information criterion (SC); e Hannan-Quinn information criterion (HQ). Quando do empate em relação aos testes com ou sem constante, o critério foi a escolha pelos menores coeficientes de cada teste. Em relação ao teste de estabilidade do VAR, todos os modelos para todas as regiões, os pontos encontram-se dentro do círculo unitário. Os resultados dos dois modelos estimados, para cada uma das regiões brasileiras, encontram-se a seguir.

\subsubsection{Impacto da política monetária sobre a preferência pela liquidez e a provisão de operações de crédito a nível regional}

A hipótese de comportamento diferenciado dos bancos a nível regional para o Brasil no período de 2003-2012 é explorada no primeiro modelo VAR o qual busca-se captar o impacto de um choque positivo na taxa de juros Selic sobre: a preferência pela liquidez bancária (primeiro bloco de gráficos); e a provisão de operações de crédito como sendo uma proxy para incerteza (segundo bloco de resultados no Gráfico 1).

Os impactos na variação da preferência pela liquidez (Liquidity_Preference) (primeiro bloco de gráficos) após o choque positivo na variação da taxa de juros revelam que para todas as regiões a preferência pela liquidez cai. Este é um comportamento esperado, tendo em vista que o aumento no custo de reter recursos ociosos aumenta com um choque positivo de juros.

\section{Gráfico 1: Função Impulso Resposta para variáveis de comportamento dos bancos por região}

\section{Região Sudeste}

Região Nordeste

Região Sul

Accumulated Response to Generalized One S.D. Innovations \pm 2 S.E. Accumulated Response to Generalized One S.D. Innovations \pm 2 S.E. Accumulated Response to Generalized One S.D. Innovations \pm 2 S.E. Accumulated Response of VAR_LLQUIDTY_PREFERENCE to D_INTEREST Accumulated Response ofVAR_LLQUIDTY_PREFERENCE to D_INTEREST Accumulated Response of VAR_LLQUIDTY_PREFERENCE to D_INTEREST

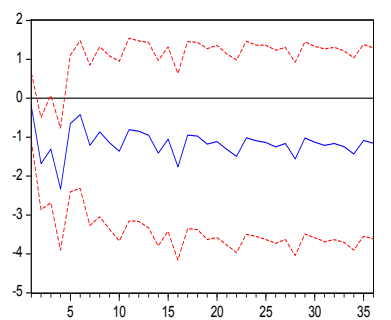

Accumulated Response of VAR_UNCERTAINTYY to D_INTEREST

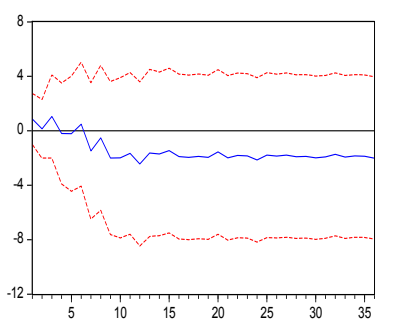

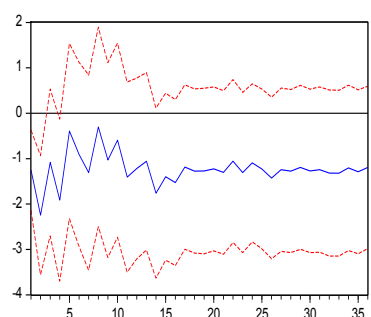

Accumulated Response of VAR_UNCERTAINTYY to D__NTEREST

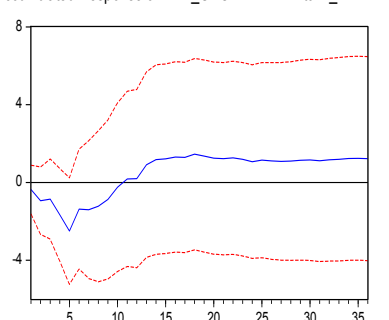

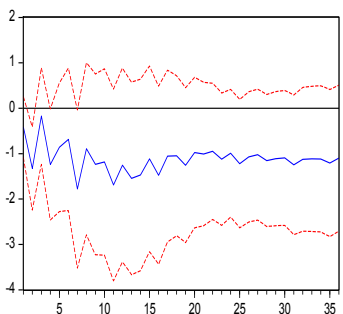

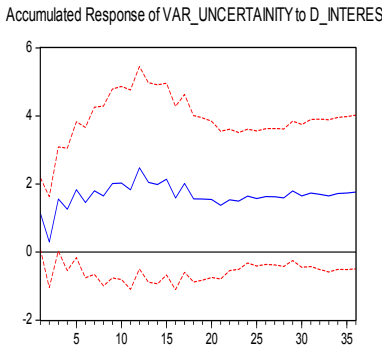


Região Centro-Oeste

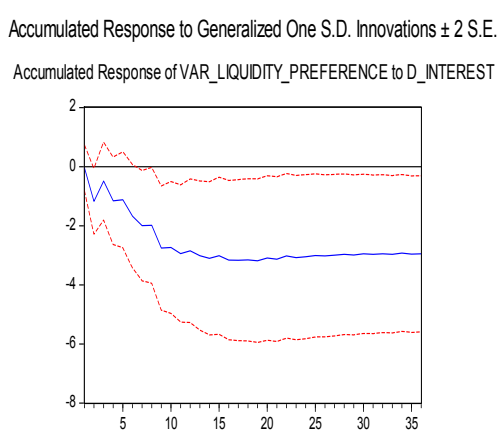

Accumulated Response of VAR_UNCERTAINTY to D__NTEREST

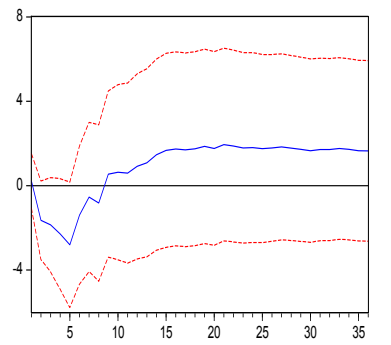

Região Norte

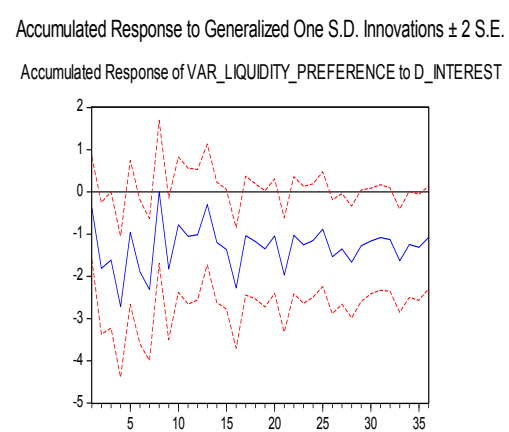

Accumulated Response of VAR_UNCERTAINITY to D_INTEREST

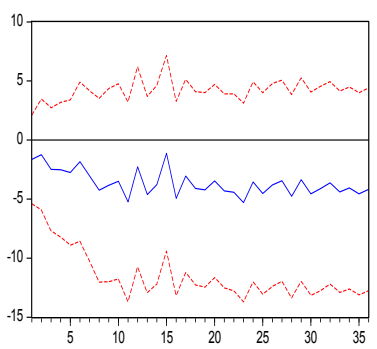

Em termos estruturais, é importante ressaltar a forte concentração das sedes dos bancos comerciais e múltiplos na região Sudeste, ou seja, dos 161 bancos existentes no Brasil em dezembro de 2012 esta região concentrava 128 sedes dos principais bancos brasileiros ${ }^{11}$. Desta forma,a região Sudeste, por concentrar quase $70 \%$ da oferta total de crédito, torna-se a única região em que o choque da taxa de juros sobre a preferência pela liquidez se estabiliza de forma mais rápida frente às outras regiões, ou seja, por volta do décimo mês após o choque de juros. ${ }^{12}$ Esse fato leva a ratificar a argumentação de Crocco (2010, p.151) que afirma a existência de uma relação entre o grau de centralidade de uma determinada região e o grau de preferência pela liquidez das agências bancárias ali instaladas. Para o autor, quanto maior a centralidade, menor será a preferência pela liquidez.

As regiões Nordeste, Sul e Centro-Oeste passam a ter um equilíbrio em suas variações de preferências pela liquidez somente após vinte meses do choque positivo de juros. Para a região Norte, após muitas oscilações, o ajuste se dá após vinte e sete meses sendo a região que levou mais tempo para estabilizar sua preferência pela liquidez.Aqui vale lembrar

\footnotetext{
${ }^{11}$ Conforme registros do Banco Central do Brasil, das 161 instituições bancárias em funcionamento no Brasil em dezembro de 2012, 102 possuíam sede no estado de São Paulo (100 na capital e duas no interior) e 15 no Rio de Janeiro. Os estados de Minas Gerais e Rio Grande do Sul têm 10 sedes cada um. O Paraná era sede de 7 instituições, sendo um deles o banco estrangeiro HSBC. Apenas 9 instituições eram mantidas como sede na região Nordeste, sendo, dentre estas, 3 localizadas na Bahia, 5 em Pernambuco, 1 no Ceará. Sergipe, Espírito Santo, Pará complementavam a lista com 1 sede apenas. Por sua vez, o Distrito Federal possuía 4 sedes sendo estas a Caixa Econômica Federal, o Banco do Brasil, o Banco de Brasília e a sede de um banco privado.

${ }^{12}$ Nesse sentido, a estabilização monetária e a abertura financeira propiciaram uma forte concentração de crédito bancário na região Sudeste, em boa parte devido à aquisição de bancos com marcada atuação nesta região. A proximidade física e a interação mais direta com os concorrentes permitiram ao sistema bancário no Sudeste desfrutar de spillover informacional e das externalidades positivas geradas pela maior concentração e, que consequentemente, possibilitaram um círculo virtuoso entre características econômicas e geração de crédito que estão sempre presentes nesta região conforme afirmam Barra e Crocco (2004).
} 
resultado encontrado em Feijó et al. (2012) mostrando que bancos localizados em regiões menos desenvolvidas perdem mais reservas do que os bancos que estão localizados nas áreas mais dinâmicas. Por isso, o maior tempo de estabilização da preferência pela liquidez por parte dos bancos em regiões menos desenvolvidas pode ser interpretado como um levando a um racionamento de crédito por mais tempo como um mecanismo de segurança de retenção de liquidez.

O segundo bloco de gráficos avalia o impacto do choque de juros na provisão de operações de crédito, proxy de incerteza, conforme utilizado por Dutra e Bastos (2016). Segundo os autores, o ajustamento a ser observado é que quando há um aumento de provisionamento para créditos não pagos e/ou duvidosos o resultado que se espera é a piora do estado de expectativa bancária quanto ao futuro do ambiente econômico levando a um aumento da incerteza. Dessa forma, o aumento nas provisões das operações de crédito é um resultado esperado quando há um choque de juros, pois este pode limitar a capacidade de solvência dos tomadores por aumentar seu custo de captação e, consequentemente, a rolagem das dívidas. Dessa forma, o aumento do nível de incerteza quanto ao ambiente econômico levaria os bancos a racionarem crédito como uma medida precaucional de retenção de liquidez.

Na região Sudeste, um choque de juros aumenta inicialmente a provisão de recursos das operações de crédito que se torna negativo após o sétimo mês do choque. É a única região a apresentar um ajustamento rápido ao choque, ou seja, uma resposta imediata de aumento de provisionamento para em seguida se observar uma queda com estabilização do provisionamento. Este comportamento era esperado e pode ser entendido como resultado de melhores ratings nas avaliações de crédito, refletidos em melhor qualidade da concessão creditícia, conforme aponta Crocco (2010, p.130). Dessa forma, torna-se plausível supor que o mercado de crédito é restabelecido após o décimo mês do choque monetário, como visto no gráfico do primeiro bloco, devido às vantagens comparativas relacionadas a concentração bancária, pela centralização financeira e pelas melhores avaliações da qualidade do crédito.

Para a região Nordeste, o efeito do aumento no provimento de recursos é retardado, assim como no Centro-Oeste. $O$ choque de juros aumenta as provisões de crédito após 0 décimo segundo mês, no primeiro caso e no oitavo mês, no segundo. Em ambos os casos pode-se sugerir que este resultado reflete uma base informacional menos precisa nas avaliações de crédito. Ou seja, o choque de juros aumenta o nível de provisionamento devido aos efeitos de carring-over dos custos dessas operações podendo tornar-se um elemento restritivo para o atendimento da demanda por novos créditos.

A região Sul apresenta uma variação positiva e imediata quanto ao impacto restritivo da política monetária sobre a variável proxy da incerteza, que persiste ao longo do tempo. Aparentemente, o impacto da proxy de incerteza não impacta a preferência pela liquidez. A região Norte, contrariando ao esperado, reduz a provisão das operações de crédito mitigando assim o nível de incerteza regional. Tanto a região Sul como a Norte apresentam resultados que sugerem que a relação entre preferência pela liquidez e provisão de recursos para créditos duvidosos não é direta.

A próxima subseção buscará mapear o entendimento de como o choque de juros pode se tornar num importante elemento restritivo à oferta de crédito em suas diversas maturidades.

\subsubsection{Impacto da política monetária via crédito a nível regional}

O segundo modelo busca captar o impacto do choque de juros sobre a oferta de crédito de diferentes maturidades para cada região. Os gráficos estão dispostos da seguinte forma: 
créditos de curto prazo (primeiro bloco); sobre os financiamentos destinados à produção (segundo bloco); e os financiamentos destinados à agricultura (terceiro bloco).

O primeiro grupo de gráficos apresenta a função impulso-resposta sobre a variação dos créditos de curto prazo (short_term), que inclui crédito a pessoas físicas, o crédito consignado, o cheque especial e o capital de giro para as empresas. No caso do crédito pessoal, O BCB (2015) ressalta seu expressivo crescimento na década dos anos 2000 sustentando o consumo agregado. ${ }^{13}$. Espera-se que um aumento na taxa de juros reduza a oferta de crédito de curto prazo. Isto é observado apenas na região Sudeste. Para esta região, após o choque positivo na variação da taxa de juros, o ajustamento se dá pela acomodação da variação da oferta de crédito de curto prazo a níveis inferiores ao observado inicialmente, ou seja, ocorre uma retração na variação da oferta dessa modalidade de empréstimos, indicando de certa forma, um "pass through" ao custo do crédito dado pelo aumento da taxa de juros.

\section{Gráfico 2: Função Impulso-Resposta para oferta de crédito de diferentes maturidades.}

\section{Região Sudeste \\ Região Nordeste \\ Região Sul}

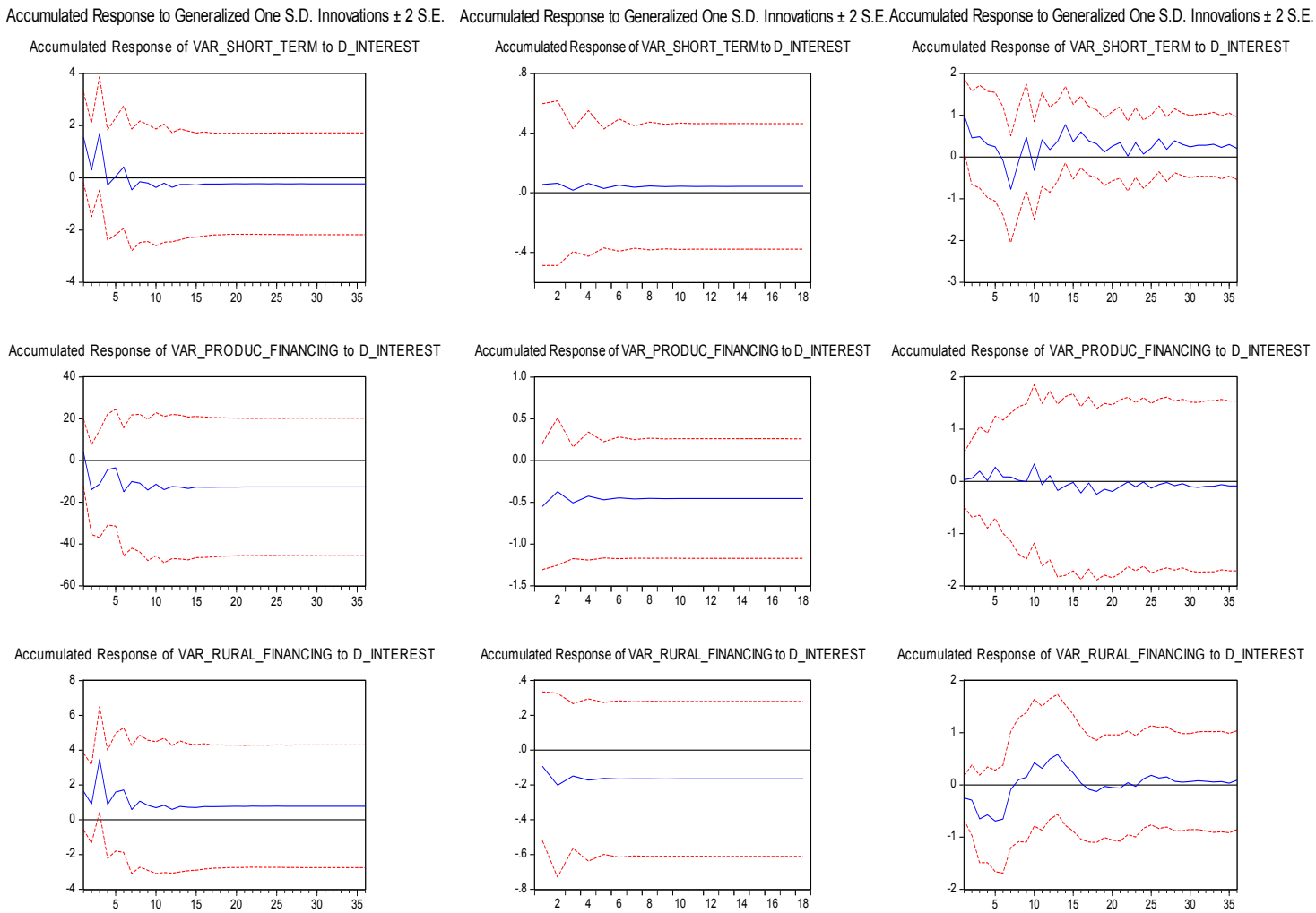

\footnotetext{
${ }^{13}$ Deve-se ressaltar que a importância relativa desta variável nas regiões menos desenvolvidas pode ser atribuída à inovação institucional relativa a criação do crédito consignado com desconto em folha de pagamento em dezembro de 2003. As instituições das regiões mais pobres apostaram neste mercado com mais intensidade justamente por ter seus riscos quase nulos dado a garantia dos recebíveis descontados na fonte geradora do fluxo financeiro.
} 
Região Centro-Oeste

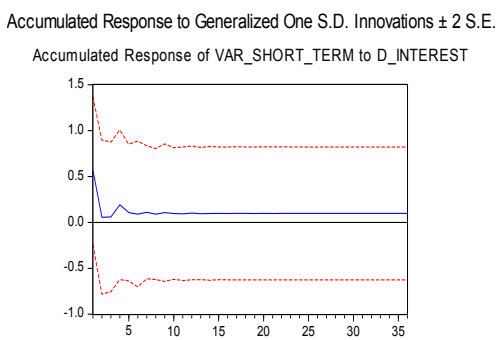

Accumulated Response of VAR_PRODUC_FINANCING to D_INTEREST

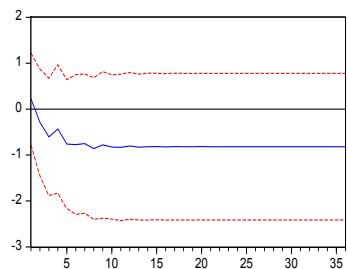

Accumulated Response of VAR_RURAL_FINANCING to D_INTEREST

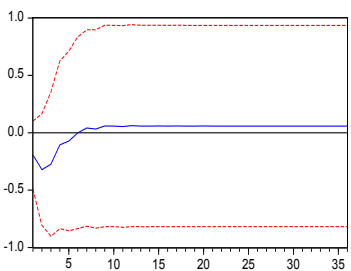

Região Norte
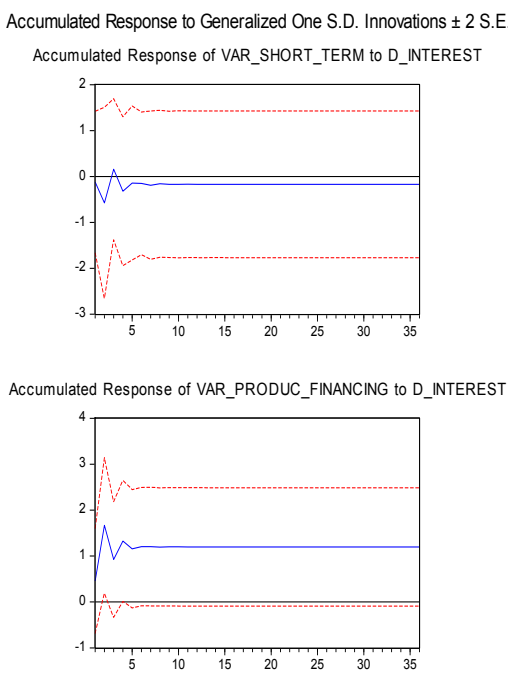

Accumulated Response of VAR_RURAL_FINANCING to D_INTEREST

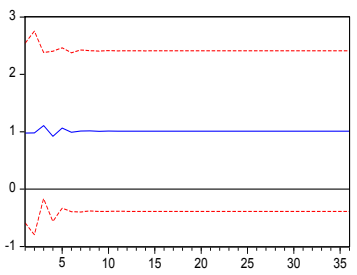

Nas regiões Nordeste e Centro-Oeste, o impacto positivo da variação da taxa de juros provoca uma queda na variação da oferta de crédito de curto prazo seguida de uma manutenção da participação dessa modalidade de empréstimos. O que pode explicar este comportamento é o baixo grau de penetração bancária nessas regiões como observado em Feijó et al; (2012, p. 28) aliado a uma baixa competição entre as instituições bancárias no sentido exposto por Belaisch $(2003, \text { p.20 })^{14}$. Neste contexto, a manutenção dos níveis positivos em termos de variação da oferta de crédito de curto prazo mesmo quando da ocorrência de um choque da taxa de juros, ressalta a baixa diversificação na oferta de serviços financeiros . A exclusão financeira, característica de regiões menos desenvolvidas acaba por impor um ajustamento perverso ao atendimento da demanda reprimida por crédito, que em um contexto de baixo nível de competição entre bancos, impõe maiores custos aos serviços financeiros em relação ao centro financeiro.

Na região Norte, a resposta ao impulso também é claramente negativa, à exceção de um breve ajustamento positivo entre o segundo e quarto meses, o que em tese, não era esperado. Por sua vez, a região Sul apresenta resultado semelhante ao das regiões Nordeste e Centro Oeste, porém a resposta ao impulso decresce até o sétimo mês após o choque, tornando-se positivo em seguida.

A baixa sensibilidade aos juros da demanda por crédito de curto prazo nas regiões menos desenvolvidas sinaliza que uma política monetária restritiva é ineficaz para conter a

\footnotetext{
${ }^{14} \mathrm{O}$ foco do estudo de Belaisch (2003) esteve atrelado ao argumento de que o setor bancário brasileiro não é plenamente competitivo. Apoiado em fatos estilizados e confirmados por investigação empírica o estudo aponta que prevalece no Brasil uma indústria bancária oligopolizada, Para a autora um maior grau de competição bancária ensejaria na minimização de custos desdobrando-se em alocações de recursos de forma eficiente. Este ajustamento, em tese, seria um foco de distribuição de benefícios do sistema bancário para outros setores da economia.
} 
demanda nestas localidades. Esta comprovação empírica, complementa as argumentações de Terra (2014) no tocante à captura da autoridade monetária pelas estratégias bancárias ao nível de regiões. A hipótese aventada pelo autor é a de que sob o regime de metas de inflação, a autoridade monetária pode ser dominada pelos bancos haja vista que são eles, em última instância, que com sua preferência pela liquidez decidem qual a magnitude da demanda agregada a ser alcançada a cada momento. ${ }^{15}$.

No segundo grupo de gráficos está o resultado da função impulso-resposta para os créditos destinados à produção (produc financing), que agrega os financiamentos a agentes financeiros, às exportações, operações de arrendamento, os financiamentos agro-industriais e os financiamentos imobiliários. Espera-se que os choques de juros impactem de forma negativa a evolução dos financiamentos destinados ao setor produtivo em virtude das instituições bancárias preferirem ativos mais líquidos, de mais curto prazo. Mais ainda, esperase que o impacto negativo seja mais forte nas regiões menos desenvolvidas, que apresentam maior nível de preferência pela liquidez.

Observa-se que o choque positivo na taxa de juros leva a uma queda na variação da oferta desse tipo de crédito para as regiões Sudeste, Nordeste e Centro Oeste. Nas regiões Nordeste e Centro-Oeste, o novo nível de equilíbrio da oferta de financiamentos se estabiliza a partir do terceiro e sexto meses, respectivamente, e leva mais tempo na região Sudeste. Tal resultado corrobora o argumento de que o tempo de resposta dos choques de juros que representam uma contração no nível de crédito na modalidade product_financing se dá em um menor prazo em regiões menos desenvolvidas que preferirão manter sua preferência pela liquidez em detrimento de ativos mais ilíquidos como os créditos de mais longo prazo.

Na região Sul, a oferta de crédito oscila em torno de seu nível inicial, sem apresentar alteração expressiva. A região Norte apresenta, de forma surpreendente uma variação positiva na oferta desse tipo de crédito. Assim, à exceção da região Norte, pode-se afirmar que no geral a resposta dos financiamentos, de mais longo prazo, aos impulsos de choques de juros para esta modalidade de crédito é claramente negativa corroborando as premissas Pós keynesianas, que, dado um aumento do custo de oportunidade, a exemplo do aumento da taxa de juros, bancos irão direcionar suas ações à ativos mais líquidos.

O terceiro grupo de gráficos apresenta o resultado da função impulso-resposta para os créditos destinados aos financiamentos rurais (ruralfinancing). Essa modalidade de financiamento agrega as contas de Agricultura e Pecuária para custeio 16 e investimento, assim como a comercialização de produtos rurais. $O$ crédito rural é tradicionalmente 0 principal instrumento de política econômica para o setor e tem impulsionado o crescimento da renda nas regiões periféricas ${ }^{17}$. No entanto, a reação a um choque de juros nesta modalidade

\footnotetext{
${ }^{15}$ Para Terra (2014), analisando criticamente a eficácia do regime de metas de inflação, mostra que a autoridade monetária perde autonomia para enfrentar o comportamento estratégico dos bancos. Isto ocorre porque os bancos obtém lucro monetário usando a rigidez imposta à autoridade monetária na busca de credibilidade para a implementação do regime de metas de inflação.

${ }^{16} \mathrm{O}$ financiamento do custeio da produção agropecuária visa as operações relacionadas à produção de grãos e/ou pecuária.

${ }^{17}$ As fontes principais dos recursos aplicados no crédito rural são compulsórias via parcela de aplicação obrigatória dos depósitos à vista nos bancos (50\% dos saldos dos financiamentos do Banco do Brasil e $75 \%$ dos aplicados pelos bancos privados) e repasses e refinanciamentos, representados pela caderneta de poupança rural, os Fundos Constitucionais, a parcela do Fundo de Amparo ao Trabalhador (FAT), do Banco Nacional de Desenvolvimento Econômico e Social (BNDES), e outros menores. No entanto, para efeitos desse estudo, a ótica utilizada seguirá os dados constantes nas estatísticas contábeis disponibilizadas pelos bancos comerciais.
} 
de crédito só não afeta as regiões Sudeste e Norte que mesmo diante do choque monetário registra variação positiva da oferta de crédito para as atividades rurais em todo o período. $\mathrm{Na}$ região Nordeste, a resposta ao impulso é negativa em todo o período. Uma situação intermediária, ou seja, de contração do crédito inicialmente e posterior recuperação é observada nas regiões Sul e Centro Oeste, as quais possuem uma clara vocação agrícola Nestas regiões, pode-se sugerir que um número expressivo de produtores rurais não estariam aptos às concessões de crédito rural com juros controlados e pré estabelecidos pelas políticas públicas, o que ocasiona uma queda na variação da oferta desse tipo de crédito, inicialmente.

Em resumo, os resultados dos exercícios econométricos permitem algumas conclusões interessantes:

a) a resposta ao impulso de um choque de juros na oferta de crédito é clara no sentido de aumentar a preferência pela liquidez em todas as regiões do país. Este resultado corrobora o trabalho seminal de Dow (1982) que afirma que bancos de atuação nacional podem emprestar menos para as regiões menos desenvolvidas, dada sua estrutura econômica e o controle remoto sobre as suas filiais;

b) a resposta ao impulso de um choque nos juros em relação à provisão de recursos para crédito varia de região para região, sugerindo que a correlação entre estas duas variáveis não é única. Dessa forma, confirma-se a hipótese de que os bancos nas regiões reagem de forma diferenciada conforme suas estratégias de defesa para a manutenção do trade off entre liquidez e rentabilidade, no sentido de Carvalho (1993). Ademais, o efeito carring-over dos custos deste choque monetário compromete a capacidade de novos tomadores de crédito que por sua vez, podem levar a um racionamento de crédito por parte dos bancos dado um aumento de provisionamento de recursos;

c) quanto à modalidade de crédito, observa-se que nas regiões menos desenvolvidas Nordeste, Centro-Oeste, e em menor grau na região Norte, um choque positivo de juros não produz uma redução na oferta de crédito de curto prazo (financiamento direto ao consumidor, cartão de crédito, financiamento de veículos e outras modalidades de crédito ao consumidor). Essas regiões apresentam baixa inserção financeira da população, o que por sua vez traz consigo a oferta de serviços financeiros simplificados, como conta correntes básicas e produtos financeiros com baixo grau de sofisticação conforme apontam Feijó et al. (2012). Ademais, o baixo nível de competição entre bancos conforme Belaisch (2003) carregam consigo o aprofundamento da exclusão financeira tanto de indivíduos como de áreas geográficas. Nesse contexto, os bancos, ao previlegiarem o crédito de curto prazo, estão em busca de maior rentabilidade para suas aplicações visto que o crédito de curto prazo possui taxas mais elevadas de remuneração do que a de outros tipos de financiamento, corroborando o estudo de Nogueira et al. (2015);

d) um resultado distinto pode ser observado em relação ao crédito destinado à produção. Neste caso o choque de juros afeta negativamente a oferta desta modalidade de crédito em todas as regiões, com exceção da região Norte. Conclui-se que o choque positivo na variação de taxa de juros é contraproducente pois aumenta o custo de captação do crédito destinado à produção, comprometendo o crescimento econômico regional. Ou seja, pode-se afirmar que a política monetária, ao não levar em conta as diferentes reações dos bancos ao choque de juros torna-se não funcional em relação ao processo de crescimento econômico das regiões menos desenvolvidas comprometendo assim a possibilidade do setor bancário em se tornar o elemento proeminente do processo de indução ao crescimento econômico e de redução de desigualdades regionais; 
e) por último, os resultados evidenciados para os impactos do crédito rural são muito interessantes, pois mostram que a oferta não se reduz após o choque de juros, à exceção da região Nordeste, que responde negativamente todo o período após o choque. Nesse contexto, infere-se que essa neutralidade em termos de impactos devese a concepção de sua modalidade estar ancorada em taxas de juros pré estabelecidas pelas políticas públicas do setor agrícola. Vale lembrar que o crédito rural é o principal instrumento de política econômica para o setor, e, portanto, o efeito da variação da taxa básica de juros tem pequeno efeito significativo sobre os custos de operação da atividade agropecuária.

\section{Comentários Finais}

A avaliação de choques de política monetária sobre a oferta de crédito regional lança luz sobre a diversidade de respostas que os bancos oferecem em cada local. Essa diversidade, segundo a literatura Pós keynesiana, está relacionada ao grau de penetração financeira dos bancos nas regiões, assim como aos movimentos de concentração bancária na região mais desenvolvida do país. Neste sentido, levantamos neste texto a hipótese de que a política monetária, ao não considerar as diferentes respostas dos bancos em cada região, pode contribuir para acentuar as disparidades regionais. Ademais, uma política monetária que não atente para os diferentes comportamentos dos bancos em cada região terá sua eficácia reduzida, pois as firmas bancárias, gerenciando seus ativos de forma diferenciada, podem ratificar ou não a sustentação da demanda agregada de acordo com sua estratégia para manter e ampliar sua rentabilidade.

Os exercícios econométricos apresentados neste artigo permitem algumas conclusões interessantes sobre o comportamento do crédito regional após um choque positivo de juros. Mostrou-se que a firma bancária se comporta discriminando sua atuação a nível regional, ou seja, gerencia seu ativo conformando rentabilidade e liquidez de acordo com o ambiente econômico avaliado pelo nível de incerteza tomado no artigo como proxy dos provimentos de operações de crédito por parte dos bancos. Neste caso, viu-se que um choque de juros afeta positivamente a provisão de operações de crédito tornando mais restritiva a oferta de crédito nas regiões Nordeste, Sul e Centro Oeste.

As evidências apresentadas também mostraram que as firmas bancárias localizadas em regiões menos desenvolvidas buscam operar via instrumentos de crédito com baixa maturidade em termos de prazos, dado o baixo grau de inserção financeira da população e a menor competitividade bancária nessas regiões privilegiando a rentabilidade bancária. Este foi o resultado observado no comportamento da oferta de crédito de curto prazo nas regiões Nordeste e Centro Oeste, e em menor grau na região Norte, que não se reduziu frente a um choque positivo de juros. Ademais, comprovou-se que há um claro distanciamento por parte da firma bancária no financiamento da produção com prazos mais longos o que compromete o papel social dos bancos em prover recursos para geração de crescimento econômico em todas as regiões..

Em conclusão, a firma bancária na alocação de seus recursos com base nas avaliações de suas percepções quanto aos retornos esperados reduz a eficácia da atuação da política monetária via canal de oferta de crédito. Ademais, considerando a política monetária no Brasil, caracteristicamente bastante restritiva, acaba por afetar de forma desigual as regiões brasileiras. E esse ajustamento perverso às regiões brasileiras compromete a possibilidade do sistema financeiro bancário em se tornar o elemento proeminente no processo de crescimento econômico podendo ter seu efeito limitado e acentuar as desigualdades regionais. 


\section{Referências}

Alexandre, M., Lima, G. T., Canuto, O. (2005), "Distribuição espacial da atividade bancária no Brasil: dimensões e indicadores", Nova Economia (UFMG), Belo Horizonte, 15(1), p. 1133.

Amado, A. (1997) Disparate Regional Development in Brazil: a monetary production approach, London: Ashgate, 360p.

Banco Central do Brasil (2015) Relatório de Inclusão Financeira, 3, Brasília.

Barra, C., Crocco, M. (2004) "Moeda e Espaço no Brasil, Um estudo de áreas selecionadas", Revista de Economia Política, 24(3).

Belaisch, A. (2003) "Do Brazilian Banks Compete?" International Found Monetary, Working Paper, WP/03/113.

Bernanke, B. e Gertler, M. (1995) "Inside the Black Box: The Credit Channel of Monetary Policy Transmission", NBER Working Paper, n.5146, p.1-45.

Bertanha, M e Haddad, E. (2008) "Efeitos Regionais da Política Monetária no Brasil: Impactos e Transbordamentos Espaciais", Revista Brasileira de Economia, 62(1), p. 3-29.

Carlino, G. A. e Defina, R. (1997) "The differential regional effects of monetary policy: evidence from the U.S. States", FRB Philadelphia Working Paper, 97-12/R.

Carvalho, F. (1993) "Sobre a endogenia da oferta de moeda: réplica ao Professor Nogueira da Costa". Revista de Economia Política, 13(3).

Carvalho, F. e Paula, L. F. (2014) "Banking in Latin America" In: A. Berger, P. Molyneux e J. Wilson (orgs.) The Oxford Handbook of Banking, New York: Oxford University Press, 1ed., p. 868-902.

Cecchetti, S. G. (1999) "Legal structure, financial strutucture, and the monetary policy transmission mechanism ". NBER Working Paper, 7151, Cambridge.

Cecchetti, S. G. e Krause, S. (2001) "Financial Structure, Macroeconomic Stability and Monetary Policy"; NBER, Working Paper 8354, Cambridge.

Chick, V. (1986) "The evolution of the banking system and the theory of saving, investment and interest", Economies et Sociétés, Cahiers de I'ISMEA, Série Monnaire et production, 3, p. 111-127.

Chick V. e Dow S. C. (1988) "Post-Keynesian perspective on the relation between banking and regional development," in P. Arestis (Ed.) Post-Keynesian Monetary Economics: New Approaches to Financial Modelling. Edward Elgar Publishing, p.219-250.

Corrêa, V. P. (2006) "Distribuição de agências bancárias e concentração financeira nas praças de maior dinamismo econômico - um estudo pra os anos 1980 e 1990". In: M. Crocco e F. Jayme Jr.. (Org.). Moeda e Território: uma interpretação da dinâmica regional brasileira. 1ed. Belo Horizonte: Editora Autêntica, 2006, p. 169-210.

Crocco, M. A. (2010) Moeda e Desenvolvimento Regional e Urbano: uma leitura Keynesiana e sua aplicação ao caso Brasileiro, Tese submetida ao Concurso de Professor Titular, CEDEPLAR, UFMG, abril.

Davidson, P. (1978) "Money and the real world", The Economic Journal, 82(325), p. 101-115.

Davidson, P. (1986) "Finance, Funding, Saving and investment", Journal of Post Keynesian Economics, 9(1), p. 101-110. 
Dow, S. C. (1982) "The regional composition of the money multiplier process", Scottish Journal of Political Economy, 29(1), February, p.22-44.

Dow. S. C. (1990) Financial Markets and Regional Economic Development: The Canadian Experience, Aldershot Brookfield, USA: Avebury, p.163-178

Dow. S. C. (1993) Money and the Economic Process, Edward Elgar Publish, July, Cambridge, $232 \mathrm{p}$.

Dutra, L. D., Bastos, J. C. A., Lamônica ,M. T. e Feijó, C. A. (2015) "Desigualdade na oferta de crédito regional a pessoa jurídica: uma análise em painel para o período 2000-2011". Economia \& Sociedade, 24, p. 681-708.

Dutra, L. D. e Bastos, J. C. A. (2016) “Atuação Regional da Firma Bancária em um Contexto de Elevada Desigualdade Regional. O Caso do Brasil: 2000-2012", Revista Cadernos do Desenvolvimento, 11(19), p.57-80.

Evangelista, T. F. e Sbardellati, E. (2016) "A eficácia do crédito como canal de transmissão da política monetária no Brasil: estratégia de identificação da oferta e demanda de crédito", 44․ Encontro Nacional de Economic ANPEC, Foz do Iguaçu, Disponível em https://goo.gl/7DkF8w, acesso em 27 de dezembro de 2016.

Ewing, B. T. (2003) "The response of the default risk premium to macroeconomic shocks", The Quarterly Review of Economics and Finance, Elsevier 43(2), p. 261-272.

Favero, C. A., Giavazzi, F., e Flabbi, L. (1999) "The Transmission Mechanism of Monetary Policy in Europe: Evidence from Banks' Balance Sheets", NBER Working Paper n.7231, Cambridge.

Feijó, C., Galeano, E. V., Dutra, L. D. e Lamônica, M.T. (2012) “Uma Análise do Crédito Bancário para Pessoas Jurídicas a partir de um Painel de Dados Regional: 2000-2008", BNDES Working Paper n.36.

Freitas, P. e Lamônica, M. T. (2015) "Estratégias Bancárias e Oferta de Crédito no Nordeste e Sudeste Brasileiro: uma avaliação através de indicadores de balanço no período 20002014", Cadernos do Desenvolvimento, 10, p. 73-92.

Fonseca, M. e Vasconcelos, M. (2002) "Impactos Diferenciados da Política Monetária nas Regiões e Estados do Brasil", II Encontro Brasileiro de Estudos Regionais e Urbanos, ABER - Associação Brasileira de Estudos Regionais, São Paulo.

Keynes, J M. (1930[1971]) "Treatise on Money", The Collected Writings of John Maynard Keynes, vol. 6, Londres: MacMillan.

Kregel, J. (1980) "Markets and institutions as features of a capitalistic production system", Journal of Post Keynesian Economics, 3(1), p-32-48.

Kregel, J. (1985). "Hamlet without the prince: macroeconomics without money". American Economic Review, 75(2), p. 133-139.

Koop, G., Pesaran, M. H. e Potter, S. M. (1996) "Impulse response analysis in nonlinear multivariate models", Journal of Econometrics, 74(1), p. 119-147.

Lutkepohl, H. (1991) New Introduction to multiple time series analysis, Springer-Verlag, Germany, 764 p.

Minsky, H. (1986) Stabilizing an unstable economy, New Haven: Yale University Press. 
Modenesi, A. M. e Modenesi, R. L. (2012) "Quinze Anos de Rigidez Monetária no Brasil pós Plano Real: uma agenda de pesquisa", Revista de Economia Política, 32(3), p.389-411.

Nogueira, M., Crocco, M., Figueiredo, A. T., e Diniz, G. (2015) "Financial hierarchy and banking strategies: a regional analysis for the Brazilian case", Cambridge Journal of Economics, vol. 39(1), p. 139-156.

Paula, L. F. (1998) “Comportamento dos Bancos, Posturas Financeiras e Oferta de Crédito: de Keynes a Minsky", Revista Análise Econômica, 16(29), p. 21-38.

Paula, L. F. (2014) Sistema Financeiro, Bancos e Financiamento da Economia: uma abordagem Keynesiana, Rio de Janeiro: Campus.

Pesaran, M. e Shin, Y. (1998) "Generalized Impulse Response Analysis in Linear Multivariate Models", Economics Letters, 58(1), p. 17-29.

Rocha, B. e Nakane, M. (2007). "O mecanismo de transmissão monetária nos estados brasileiros: uma abordagem do modelo de fatores dinâmicos", Seminário USP de Economia, Disponível em https://goo.gl/bjbYGj

Rocha, M. R., Silva, M. E. e Gomes, M. (2011) "Por que os Estados Brasileiros tem Reações Assimétricas a Choques na Política Monetária?", Revista Brasileira de Econometria, Rio de Janeiro, 65(4), p.413-441.

Rodriguez-Fuentes, C. J. (1996) "Política Monetária Y Economia Regional”, Consejo Economico Y Social, Madrid.

Rodriguez-Fuentes, C. J. (1998) "Credit availability and regional development", Papers in Regional Science, 77(1), p. 63-75.

Rodriguez-Fuentes, C. J. e Dow, S. C. (2003) "EMU and the regional impact of monetary policy", Regional Studies, 37(9), p.969-980.

Rodriguez-Fuentes, C. J. e Padron-Marrero, D. (2008) "Industry effects of monetary policy in Spain", Regional Studies, 42(3), p.375-384.

Sims, C. A. (1980) "Macroeconomics and Reality”, Econometrica, 48(1), pp. 1-48,.

Sims, C. A., Stock, J. H. e Watson, M. V. (1990) "Inference in Linear Time Series Models whit some Unit Roots", Econometrica, 58(1). pp. 113-144.

Svensson, E. (2012) "Regional effects of monetary policy in Sweden", Working Paper, n.2012:9, Lund University, p.1-31.

Terra, F. (2014) “Uma interpretação Pós keynesiana do Regime de Metas de Inflação: poderia a Autoridade Monetária ser capturada pelo sistema bancário?" Revista da Sociedade Brasileira de Economia Política, 38, p. 108-126. 


\section{APÊNDICE A}

\section{Descrição da base de dados:}

A base de dados - Estatísticas Bancárias por Municípios - ESTBAN, disponível no Banco Central do Brasil, disponibiliza dados financeiros apresentados em 83 contas. Os dados estão disponíveis a preços correntes. Os dados foram tabulados e somados por Unidades Federativas e agregados por regiões geográficas brasileiras. Foram utilizados os valores mensais do período Janeiro/2003 a dezembro/2012. Para construção das variáveis utilizadas no modelo foram utilizadas as contas conforme quadro 01 .

Quadro 01. Contas Estatísticas Bancárias por Municípios - ESTBAN

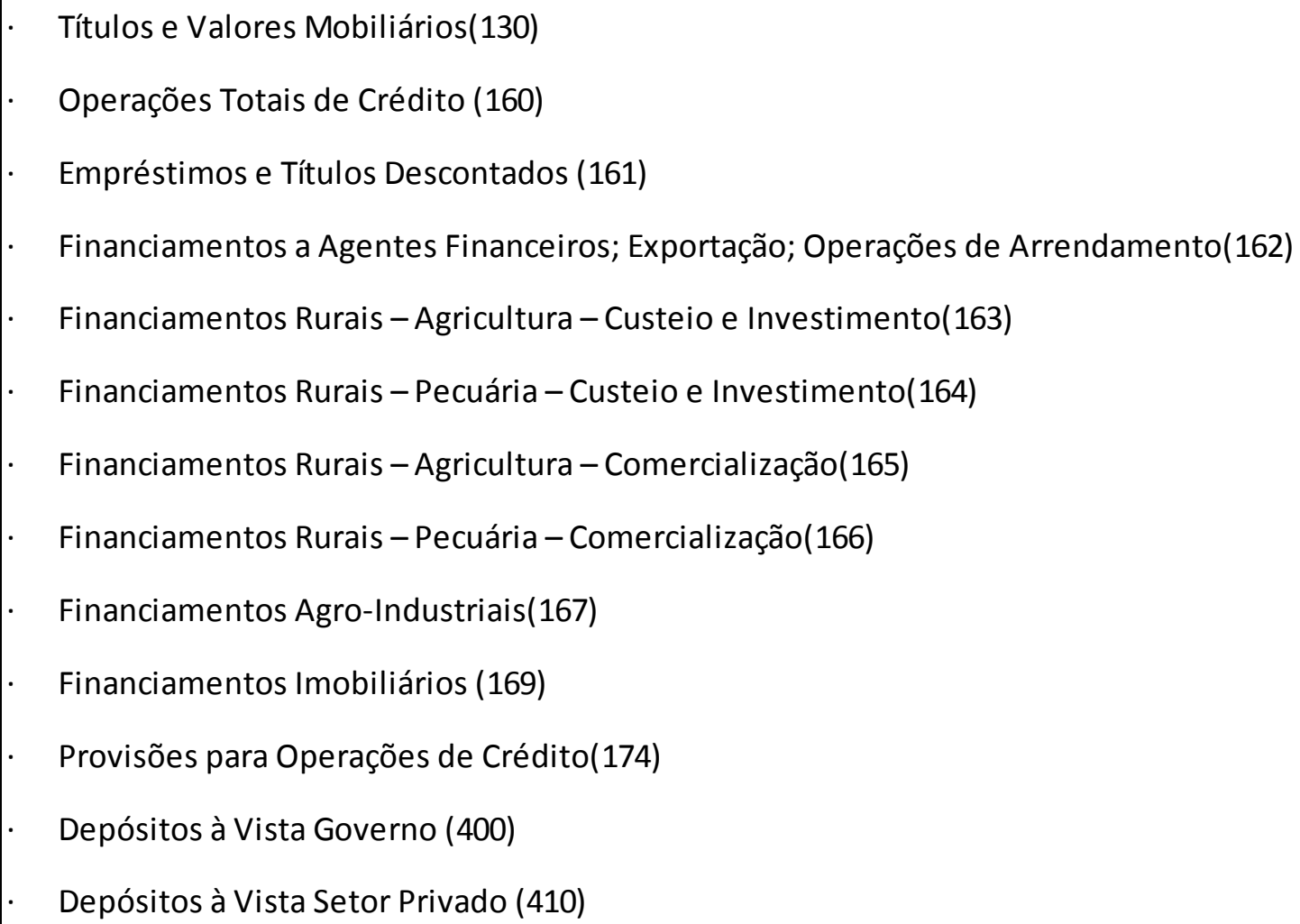

APÊNDICE B

Descrição da base de dados conforme quadro 02

Quadro 02. Agregação das Contas Estatísticas Bancárias por Municípios - ESTBAN 
- $\quad$ Short_Term - Conta Empréstimos e Títulos Descontados (161).

Produc_Financing - Agregação das contas: Financiamentos a Agentes Financeiros; Exportação; Operações de Arrendamento(162), Financiamentos Agro-Industriais(167), Financiamentos Imobiliários (169).

Rural_Financing - Agregação das contas: Financiamentos Rurais - Agricultura - Custeio e Investimento(163), Financiamentos Rurais - Pecuária - Custeio e Investimento(164), Financiamentos Rurais - Agricultura - Comercialização(165), Financiamentos Rurais Pecuária-Comercialização(166).

Liquidity_Preference - a razão entre o depósito à vista do setor privado(conta 410) e do governo(conta 400) pelas operações de crédito total(conta 160) das regiões.

Uncertainity - Provisões para Operações de Crédito(174).

\section{APÊNDICE C}

Quadro 1 - Testes de Raiz Unitária - Região Sudeste

\begin{tabular}{|l|c|c|c|c|c|c|}
\hline \multirow{2}{*}{ Variável } & \multicolumn{2}{|c|}{ ADF } & \multicolumn{2}{c|}{ PP } & \multicolumn{2}{c|}{ KPSS } \\
\cline { 2 - 7 } & t-estatístico & valor crítico 5\% & t-estatístico & valor crítico $5 \%$ & t-estatístico & valor crítico 5\% \\
\hline var_interest & -4.17 & -3.44 & -20.87 & -3.43 & 0.06 & 0.14 \\
var_liquitdity_preference & -3.47 & -3.44 & -26.92 & -3.43 & 0.08 & 0.14 \\
var_uncertainity & -23.77 & -3.43 & -22.96 & -3.43 & 0.06 & 0.14 \\
var_short_term & -13.92 & -3.43 & -26.91 & -3.43 & 0.09 & 0.14 \\
var_produc_financing & -14.02 & -3.43 & -14.04 & -3.43 & 0.05 & 0.14 \\
var_rural_financing & -24.01 & -3.43 & -25.06 & -3.43 & 0.06 & 0.14 \\
\hline
\end{tabular}

Fonte: Elaboração dos autores. Todos os testes foram feitos com intercepto e tendência.

Quadro 2 - Testes de Raiz Unitária - Região Nordeste

\begin{tabular}{|l|c|c|c|c|c|c|}
\hline \multirow{2}{*}{\multicolumn{1}{|c|}{ Variável }} & \multicolumn{2}{c|}{ ADF } & \multicolumn{2}{c|}{ PP } & \multicolumn{2}{c|}{ KPSS } \\
\cline { 2 - 7 } & t-estatístico & valor crítico 5\% & t-estatístico & valor crítico 5\% & t-estatístico & valor crítico 5\% \\
\hline var_interest & -4.17 & -3.44 & -20.87 & -3.43 & 0.06 & 0.14 \\
var_liquitdity_preference & -3.70 & -3.44 & -42.23 & -3.43 & 0.50 & 0.14 \\
var_uncertainity & -13.68 & -3.43 & -13.69 & -3.43 & 0.05 & 0.14 \\
var_short_term & -17.71 & -3.43 & -17.88 & -3.43 & 0.08 & 0.14 \\
var_produc_financing & -12.98 & -3.43 & -12.97 & -3.43 & 0.04 & 0.14 \\
var_rural_financing & -12.53 & -3.43 & -12.60 & -3.43 & 0.11 & 0.14 \\
\hline
\end{tabular}

Fonte: Elaboração dos autores. Todos os testes foram feitos com intercepto e tendência. 
Quadro 3 - Testes de Raiz Unitária - Região Sul

\begin{tabular}{|l|c|c|c|c|c|c|}
\hline \multirow{2}{*}{ Variável } & \multicolumn{2}{c|}{ ADF } & \multicolumn{2}{c|}{ PP } & \multicolumn{2}{c|}{ KPSS } \\
\cline { 2 - 7 } & t-estatístico & valor crítico 5\% & t-estatístico & valor crítico 5\% & t-estatístico & valor crítico 5\% \\
\hline var_interest & -4.17 & -3.44 & -20.87 & -3.43 & 0.06 & 0.14 \\
var_liquitdity_preference & -3.02 & -3.44 & -18.90 & -3.43 & 0.06 & 0.14 \\
var_uncertainity & -15.96 & -3.43 & -15.99 & -3.43 & 0.05 & 0.14 \\
var_short_term & -18.34 & -3.43 & -27.59 & -3.43 & 0.12 & 0.14 \\
var_produc_financing & -13.36 & -3.43 & -13.42 & -3.43 & 0.08 & 0.14 \\
var_rural_financing & -10.07 & -3.43 & -11.16 & -3.43 & 0.08 & 0.14 \\
\hline
\end{tabular}

Fonte: Elaboração dos autores. Todos os testes foram feitos com intercepto e tendência.

Quadro 4 - Testes de Raiz Unitária - Região Centro-Oeste

\begin{tabular}{|l|c|c|c|c|c|c|}
\hline \multirow{2}{*}{ Variável } & \multicolumn{2}{c|}{ ADF } & \multicolumn{2}{c|}{ PP } & \multicolumn{2}{c|}{ KPSS } \\
\cline { 2 - 7 } & t-estatístico & valor crítico 5\% & t-estatístico & valor crítico 5\% & t-estatístico & valor crítico 5\% \\
\hline var_interest & -4.17 & -3.44 & -20.87 & -3.43 & 0.06 & 0.14 \\
var_liquitdity_preference & -14.21 & -3.43 & -14.25 & -3.43 & 0.06 & 0.14 \\
var_uncertainity & -12.63 & -3.43 & -13.13 & -3.43 & 0.07 & 0.14 \\
var_short_term & -13.27 & -3.43 & -18.62 & -3.43 & 0.11 & 0.14 \\
var_produc_financing & -14.21 & -3.43 & -14.25 & -3.43 & 0.05 & 0.14 \\
var_rural_financing & -14.93 & -3.43 & -17.54 & -3.43 & 0.06 & 0.14 \\
\hline
\end{tabular}

Fonte: Elaboração dos autores. Todos os testes foram feitos com intercepto e tendência.

Quadro 5 - Testes de Raiz Unitária - Região Norte

\begin{tabular}{|l|c|c|c|c|c|c|}
\hline \multirow{2}{*}{ Variável } & \multicolumn{2}{c|}{ ADF } & \multicolumn{2}{c|}{ PP } & \multicolumn{2}{c|}{ KPSS } \\
\cline { 2 - 7 } & t-estatístico & valor crítico 5\% & t-estatístico & valor crítico 5\% & t-estatístico & valor crítico 5\% \\
\hline var_interest & -4.17 & -3.44 & -20.87 & -3.43 & 0.06 & 0.14 \\
var_liquitdity_preference & -5.17 & -3.44 & -29.90 & -3.43 & 0.15 & 0.14 \\
var_uncertainity & -18.39 & -3.43 & -19.15 & -3.43 & 0.04 & 0.14 \\
var_short_term & -11.88 & -3.43 & -19.87 & -3.43 & 0.08 & 0.14 \\
var_produc_financing & -13.04 & -3.43 & -13.08 & -3.43 & 0.08 & 0.14 \\
var_rural_financing & -15.14 & -3.43 & -15.26 & -3.43 & 0.04 & 0.14 \\
\hline
\end{tabular}

Fonte: Elaboração dos autores. Todos os testes foram feitos com intercepto e tendência. 


\section{APÊNDICE D}

Quadro 6 - Resultados dos Testes para Ordem do VAR - Comportamento dos Bancos - Região Sudeste

\begin{tabular}{|c|c|c|c|c|c|c|c|c|c|c|}
\hline \multirow{2}{*}{ Ordem do VAR } & \multicolumn{9}{|c|}{ Com Constante } & \multicolumn{4}{|c|}{ Sem Constante } \\
\cline { 2 - 9 } & LR & FPE & AIC & SC & HQ & LR & FPE & AIC & SC & HQ \\
\hline 0 & NA & $6.18 \mathrm{E}+10$ & 39.0358 & 39.13752 & 39.07713 & - & - & - & - & - \\
1 & 255.3548 & $1.42 \mathrm{E}+10$ & 37.56491 & $38.17520 *$ & 37.81288 & NA & $1.51 \mathrm{E}+10$ & 37.62829 & $38.13687 *$ & 37.83493 \\
2 & 91.4452 & $1.02 \mathrm{E}+10$ & 37.23266 & 38.35152 & $37.68726 *$ & 80.37065 & $1.18 \mathrm{E}+10$ & 37.38178 & 38.39894 & $37.79506 *$ \\
3 & 51.27383 & $9.71 \mathrm{E}+09$ & 37.18139 & 38.80883 & 37.84264 & 53.40571 & $1.11 \mathrm{E}+10$ & 37.31733 & 38.84306 & 37.93725 \\
4 & 46.26781 & $9.50 \mathrm{E}+09$ & 37.15432 & 39.29034 & 38.02221 & 29.64042 & $1.24 \mathrm{E}+10$ & 37.42408 & 39.45838 & 38.25064 \\
5 & 63.15363 & $7.99 \mathrm{E}+09$ & 36.97252 & 39.61712 & 38.04705 & 62.17144 & $1.06 \mathrm{E}+10$ & 37.25461 & 39.7975 & 38.28781 \\
6 & 59.77232 & $6.80 \mathrm{E}+09$ & 36.79738 & 39.95056 & 38.07855 & 89.87496 & $6.98 \mathrm{E}+09$ & 36.82658 & 39.87805 & 38.06643 \\
7 & $45.28966 *$ & $6.47 \mathrm{e}+09 *$ & $36.72950 *$ & 40.39126 & 38.21731 & $40.99727 *$ & $6.92 \mathrm{e}+09 *$ & $36.80067 *$ & 40.36071 & 38.24716 \\
\hline
\end{tabular}

Fonte: Elaboração dos autores

Nota: * denota a ordem de defasagem por critério

LR: sequential modified LR test statistic (each test at $5 \%$ level)

FPE: Final prediction error

AIC: Akaike information criterion

SC: Schwarz information criterion

HQ: Hannan-Quinn information criterion

Quadro 7 - Resultados dos Testes para Ordem do VAR - Comportamento dos Bancos - Região Nordeste

\begin{tabular}{|c|c|c|c|c|c|c|c|c|c|c|}
\hline \multirow{2}{*}{ Ordem do VAR } & \multicolumn{5}{|c|}{ Com Constante } & \multicolumn{5}{|c|}{ Sem Constante } \\
\hline & LR & FPE & AIC & SC & $\mathrm{HQ}$ & LR & FPE & AIC & SC & $\mathrm{HQ}$ \\
\hline 0 & NA & $1.39 \mathrm{E}+10$ & 37.54809 & 37.64981 & 37.58942 & - & - & - & - & - \\
\hline 1 & 150.3078 & $6.75 E+09$ & 36.82222 & $37.43251^{*}$ & 37.07019 & NA & 7.37E+09 & 36.90966 & $37.41824 *$ & 37.1163 \\
\hline 2 & 62.10723 & $6.02 E+09$ & 36.70568 & 37.82455 & 37.16029 & 44.93691 & $7.46 \mathrm{E}+09$ & 36.92179 & 37.93894 & 37.33507 \\
\hline 3 & 50.33297 & $5.77 E+09$ & 36.6616 & 38.28904 & 37.32285 & 50.76163 & $7.16 E+09$ & 36.87737 & 38.4031 & 37.49729 \\
\hline 4 & 71.45551 & $4.63 E+09$ & 36.43463 & 38.57065 & 37.30252 & 27.51796 & $8.14 \mathrm{E}+09$ & 37.00083 & 39.03513 & 37.82739 \\
\hline 5 & 112.3985 & $2.59 \mathrm{E}+09$ & 35.84585 & 38.49045 & 36.92038 & 83.93989 & $5.79 \mathrm{E}+09$ & 36.65293 & 39.19582 & 37.68613 \\
\hline 6 & 113.0208 & $1.39 \mathrm{E}+09$ & 35.21167 & 38.36485 & $36.49284 *$ & 195.3582 & $1.55 \mathrm{E}+09$ & 35.32334 & 38.3748 & $36.56318^{*}$ \\
\hline 7 & $41.47734^{*}$ & $1.37 e+09^{*}$ & 35.17814 & 38.83989 & 36.66595 & $40.51142 *$ & $1.55 e+09 *$ & $35.30177 *$ & 38.8618 & 36.74825 \\
\hline 8 & 36.71568 & $1.40 \mathrm{E}+09$ & $35.17190 *$ & 39.34223 & 36.86635 & 29.3262 & $1.69 \mathrm{E}+09$ & 35.36782 & 39.43644 & 37.02095 \\
\hline
\end{tabular}

Fonte: Elaboração dos autores

Nota: * denota a ordem de defasagem por critério

LR: sequential modified LR test statistic (each test at 5\% level)

FPE: Final prediction error

AIC: Akaike information criterion

SC: Schwarz information criterion

HQ: Hannan-Quinn information criterion

Quadro 8 - Resultados dos Testes para Ordem do VAR - Comportamento dos Bancos - Região Sul

\begin{tabular}{|c|c|c|c|c|c|c|c|c|c|c|}
\hline \multirow{2}{*}{ Ordem do VAR } & \multicolumn{5}{|c|}{ Com Constante } & \multicolumn{5}{|c|}{ Sem Constante } \\
\hline & LR & FPE & AIC & SC & $\mathrm{HQ}$ & $\mathrm{LR}$ & FPE & AIC & SC & $\mathrm{HQ}$ \\
\hline 0 & NA & $5.43 E+09$ & 36.6054 & 36.70712 & 36.64673 & - & - & - & - & - \\
\hline 1 & 170.809 & $2.27 \mathrm{E}+09$ & 35.73412 & $36.34442^{*}$ & 35.98209 & NA & $2.44 \mathrm{E}+09$ & 35.80584 & $36.31442 *$ & 36.01248 \\
\hline 2 & 68.66077 & $1.93 \mathrm{E}+09$ & 35.5694 & 36.68827 & 36.02401 & 52.68644 & $2.34 \mathrm{E}+09$ & 35.7614 & 36.77856 & 36.17468 \\
\hline 3 & 51.82404 & $1.83 \mathrm{E}+09$ & 35.51393 & 37.14138 & 36.17518 & 45.89614 & $2.33 E+09$ & 35.75384 & 37.27957 & 36.37376 \\
\hline 4 & 75.24426 & $1.42 \mathrm{E}+09$ & 35.25689 & 37.39292 & 36.12478 & 36.23096 & $2.47 \mathrm{E}+09$ & 35.80869 & 37.843 & 36.63525 \\
\hline 5 & 117.9694 & $7.62 E+08$ & 34.62208 & 37.26668 & 35.69661 & 76.32816 & $1.87 \mathrm{E}+09$ & 35.52319 & 38.06607 & 36.55639 \\
\hline 6 & 103.1661 & $4.46 \mathrm{E}+08$ & 34.07285 & 37.22603 & $35.35402^{*}$ & 197.9209 & $4.91 \mathrm{E}+08$ & 34.17169 & 37.22315 & $35.41153^{*}$ \\
\hline 7 & $47.85654 *$ & $4.15 e+08 *$ & 33.98185 & 37.6436 & 35.46966 & $47.67130 *$ & $4.58 e+08 *$ & $34.08619 *$ & 37.64623 & 35.53267 \\
\hline 8 & 36.95543 & $4.22 \mathrm{E}+08$ & $33.97335 *$ & 38.14368 & 35.6678 & 33.43209 & $4.83 E+08$ & 34.11388 & 38.18249 & 35.767 \\
\hline
\end{tabular}

Fonte: Elaboração dos autores

Nota: * denota a ordem de defasagem por critério

LR: sequential modified LR test statistic (each test at $5 \%$ level)

FPE: Final prediction error

AIC: Akaike information criterion

SC: Schwarz information criterion

HQ: Hannan-Quinn information criterion 
Quadro 9-Resultados dos Testes para Ordem do VAR - Comportamento dos Bancos - Região Centro-Oeste

\begin{tabular}{|c|c|c|c|c|c|c|c|c|c|c|}
\hline \multirow{2}{*}{ Ordem do VAR } & \multicolumn{5}{|c|}{ Com Constante } & \multicolumn{5}{|c|}{ Sem Constante } \\
\hline & LR & FPE & AIC & SC & $\mathrm{HQ}$ & LR & FPE & AIC & SC & $\mathrm{HQ}$ \\
\hline 0 & NA & $2.11 \mathrm{E}+10$ & 37.96172 & 38.06344 & 38.00305 & - & - & - & - & - \\
\hline 1 & 127.7678 & $1.20 \mathrm{E}+10$ & 37.3957 & $38.00599 *$ & 37.64367 & NA & $1.34 \mathrm{E}+10$ & 37.51065 & $38.01922 *$ & 37.71729 \\
\hline 2 & 39.296 & $1.26 \mathrm{E}+10$ & 37.4469 & 38.56577 & 37.90151 & 33.13617 & $1.48 \mathrm{E}+10$ & 37.60891 & 38.62607 & 38.02219 \\
\hline 3 & 45.53445 & $1.26 \mathrm{E}+10$ & 37.43944 & 39.06689 & 38.10069 & 36.31153 & $1.59 \mathrm{E}+10$ & 37.67396 & 39.19969 & 38.29388 \\
\hline 4 & 48.11071 & $1.21 \mathrm{E}+10$ & 37.39775 & 39.53377 & 38.26564 & 27.04515 & $1.81 \mathrm{E}+10$ & 37.80114 & 39.83545 & 38.6277 \\
\hline 5 & 94.92233 & $7.84 \mathrm{E}+09$ & 36.9534 & 39.598 & 38.02793 & 42.82882 & $1.81 \mathrm{E}+10$ & 37.79022 & 40.33311 & 38.82342 \\
\hline 6 & $140.5493 *$ & $3.32 \mathrm{e}+09 *$ & $36.08191^{*}$ & 39.23508 & $37.36308^{*}$ & $227.6082 *$ & $3.67 e+09 *$ & $36.18499 *$ & 39.23645 & $37.42483^{*}$ \\
\hline
\end{tabular}

Fonte: Elaboração dos autores

Nota: * denota a ordem de defasagem por critério

LR: sequential modified LR test statistic (each test at $5 \%$ level)

FPE: Final prediction error

AIC: Akaike information criterion

SC: Schwarz information criterion

$\mathrm{HQ}$ : Hannan-Quinn information criterion

Quadro 10 - Resultados dos Testes para Ordem do VAR - Comportamento dos Bancos - Região Norte

\begin{tabular}{|c|c|c|c|c|c|c|c|c|c|c|}
\hline \multirow{2}{*}{ Ordem do VAR } & \multicolumn{5}{|c|}{ Com Constante } & \multicolumn{5}{|c|}{ Sem Constante } \\
\hline & LR & FPE & AIC & SC & $\mathrm{HQ}$ & LR & FPE & AIC & SC & $\mathrm{HQ}$ \\
\hline 0 & NA & $2.96 \mathrm{E}+11$ & 40.60401 & 40.70572 & 40.64534 & - & - & - & - & - \\
\hline 1 & 141.4167 & $1.53 \mathrm{E}+11$ & 39.94119 & $40.55148^{*}$ & 40.18916 & NA & $1.74 \mathrm{E}+11$ & 40.07075 & $40.57933^{*}$ & 40.27739 \\
\hline 2 & 61.98763 & $1.36 \mathrm{E}+11$ & 39.82553 & 40.9444 & 40.28014 & 52.10166 & $1.67 \mathrm{E}+11$ & 40.03058 & 41.04774 & 40.44386 \\
\hline 3 & 68.15242 & $1.14 \mathrm{E}+11$ & 39.64542 & 41.27287 & 40.30667 & 66.04173 & $1.43 \mathrm{E}+11$ & 39.8704 & 41.39613 & 40.49032 \\
\hline 4 & 68.85142 & $9.33 \mathrm{E}+10$ & 39.43912 & 41.57514 & 40.30701 & 48.04165 & $1.38 \mathrm{E}+11$ & 39.83226 & 41.86656 & 40.65882 \\
\hline 5 & 123.4138 & 4.77E+10 & 38.75931 & 41.40391 & 39.83383 & 65.02334 & $1.15 \mathrm{E}+11$ & 39.63941 & 42.1823 & 40.67262 \\
\hline 6 & 150.7902 & $1.85 \mathrm{E}+10$ & 37.79953 & 40.9527 & 39.0807 & 251.1346 & $1.91 \mathrm{E}+10$ & 37.8331 & 40.88456 & 39.07294 \\
\hline 7 & 76.00581 & $1.34 \mathrm{E}+10$ & 37.45492 & 41.11668 & $38.94274^{*}$ & 73.60261 & $1.42 \mathrm{E}+10$ & 37.51607 & 41.07611 & $38.96255^{*}$ \\
\hline 8 & 41.37157* & $1.30 \mathrm{e}+10^{*}$ & $37.40476 *$ & 41.57509 & 39.09921 & $43.34122 *$ & $1.36 \mathrm{e}+10 *$ & $37.45115^{*}$ & 41.51976 & 39.10427 \\
\hline
\end{tabular}

Fonte: Elaboração dos autores

Nota: * denota a ordem de defasagem por critério

LR: sequential modified LR test statistic (each test at $5 \%$ level)

FPE: Final prediction error

AIC: Akaike information criterion

SC: Schwarz information criterion

HQ: Hannan-Quinn information criterion

Quadro 11 - Resultados dos Testes para Ordem do VAR - Oferta de Crédito - Região Sudeste

\begin{tabular}{|c|c|c|c|c|c|c|c|c|c|c|}
\hline \multirow{2}{*}{ Ordem do VAR } & \multicolumn{5}{|c|}{ Com Constante } & \multicolumn{5}{|c|}{ Sem Constante } \\
\hline & LR & FPE & AIC & SC & $\mathrm{HQ}$ & LR & FPE & AIC & SC & $\mathrm{HQ}$ \\
\hline 0 & NA & $1.75 E+08$ & 30.32945 & 30.42236 & 30.36718 & - & - & - & - & - \\
\hline 1 & 107.3991 & $8.96 \mathrm{E}+07$ & 29.66221 & $30.12679 *$ & $29.85088^{*}$ & NA & $8.93 E+07$ & 29.65899 & $30.03065 *$ & $29.80992 *$ \\
\hline 2 & 35.54972 & $8.50 \mathrm{E}+07$ & 29.60861 & 30.44485 & 29.94821 & 32.66509 & $8.72 E+07$ & 29.63400 & 30.37733 & 29.93587 \\
\hline 3 & 44.67467 & 73269778* & $29.45775^{*}$ & 30.66567 & 29.94829 & 43.78197 & 76015978* & $29.49528 *$ & 30.61028 & 29.94808 \\
\hline 4 & 21.35106 & $7.81 E+07$ & 29.51713 & 31.09671 & 30.1586 & 19.02415 & $8.30 \mathrm{E}+07$ & 29.57902 & 31.06568 & 30.18276 \\
\hline 5 & 26.5894 & $7.85 \mathrm{E}+07$ & 29.51521 & 31.46646 & 30.30762 & 25.95446 & $8.41 E+07$ & 29.58614 & 31.44447 & 30.34082 \\
\hline 6 & 26.27227 & $7.85 \mathrm{E}+07$ & 29.50533 & 31.82824 & 30.44867 & 26.71163 & $8.39 \mathrm{E}+07$ & 29.57456 & 31.80456 & 30.48017 \\
\hline 7 & 9.489558 & $9.37 \mathrm{E}+07$ & 29.66772 & 32.36229 & 30.762 & 11.03271 & $9.84 \mathrm{E}+07$ & 29.72131 & 32.32297 & 30.77786 \\
\hline 8 & $31.60313 *$ & 86680516 & 29.57113 & 32.63737 & 30.81634 & $26.54656 *$ & 96750358 & 29.68631 & 32.65964 & 30.89379 \\
\hline
\end{tabular}

Fonte: Elaboração dos autores

Nota: * denota a ordem de defasagem por critério

LR: sequential modified LR test statistic (each test at $5 \%$ level)

FPE: Final prediction error

AIC: Akaike information criterion

SC: Schwarz information criterion

HQ: Hannan-Quinn information criterion 
Quadro 12 - Resultados dos Testes para Ordem do VAR - Oferta de Crédito - Região Nordeste

\begin{tabular}{|c|c|c|c|c|c|c|c|c|c|c|}
\hline \multirow{2}{*}{ Ordem do VAR } & \multicolumn{5}{|c|}{ Com Constante } & \multicolumn{5}{|c|}{ Sem Constante } \\
\hline & LR & FPE & AIC & SC & $\mathrm{HQ}$ & LR & FPE & AIC & SC & $\mathrm{HQ}$ \\
\hline 0 & NA & $2.48 \mathrm{E}+03$ & 19.16732 & 19.26024 & 19.20506 & - & - & - & - & - \\
\hline 1 & 80.06403 & $1613.989 *$ & $18.73778 *$ & $19.20236 *$ & $18.92645 *$ & NA & $2.60 \mathrm{E}+03$ & 19.21456 & $19.58622 *$ & 19.36549* \\
\hline 2 & 26.09869 & $1.67 \mathrm{E}+03$ & 18.76932 & 19.60557 & 19.10893 & 28.51712 & $2.63 \mathrm{E}+03$ & 19.22661 & 19.96994 & 19.52848 \\
\hline 3 & 29.46969 & $1.66 \mathrm{E}+03$ & 18.76057 & 19.96848 & 19.25111 & 45.26739 & $2.26 \mathrm{E}+03$ & 19.07413 & 20.18913 & 19.52693 \\
\hline 4 & 22.976 & $1.74 \mathrm{E}+03$ & 18.80417 & 20.38375 & 19.44564 & 28.80823 & $2.25 \mathrm{E}+03$ & 19.06379 & 20.55046 & 19.66753 \\
\hline 5 & 20.0165 & $1.87 E+03$ & 18.86865 & 20.81989 & 19.66106 & 29.53526 & $2.20 \mathrm{E}+03$ & 19.03511 & 20.89344 & 19.78978 \\
\hline 6 & 28.43131 & $1.82 \mathrm{E}+03$ & 18.83604 & 21.15895 & 19.77938 & 28.30674 & $2158.708 *$ & $19.00691 *$ & 21.23691 & 19.91252 \\
\hline 7 & 11.21021 & $2.14 \mathrm{E}+03$ & 18.97952 & 21.67409 & 20.0738 & 9.714375 & $2.57 E+03$ & 19.16799 & 21.76965 & 20.22453 \\
\hline 8 & $26.34039 *$ & $2.10 E+03$ & 18.94342 & 22.00966 & 20.18864 & $29.61536 *$ & $2.44 \mathrm{E}+03$ & 19.09812 & 22.07144 & 20.3056 \\
\hline
\end{tabular}

Fonte: Elaboração dos autores

Nota: * denota a ordem de defasagem por critério

LR: sequential modified LR test statistic (each test at $5 \%$ level)

FPE: Final prediction error

AIC: Akaike information criterion

SC: Schwarz information criterion

HQ: Hannan-Quinn information criterion

Quadro 13 - Resultados dos Testes para Ordem do VAR - Oferta de Crédito - Região Sul

\begin{tabular}{|c|c|c|c|c|c|c|c|c|c|c|}
\hline \multirow{2}{*}{ Ordem do VAR } & \multicolumn{5}{|c|}{ Com Constante } & \multicolumn{5}{|c|}{ Sem Constante } \\
\hline & LR & FPE & AIC & SC & $\mathrm{HQ}$ & LR & FPE & AIC & SC & $\mathrm{HQ}$ \\
\hline 0 & NA & $9.69 E+03$ & 20.52993 & 20.62284 & 20.56766 & - & - & - & - & - \\
\hline 1 & 166.0057 & $2.99 E+03$ & 19.35307 & $19.81765^{*}$ & 19.54173 & NA & $4.99 \mathrm{E}+03$ & 19.86674 & 20.23841 & 20.01768 \\
\hline 2 & 49.82489 & $2.49 E+03$ & 19.17086 & 20.00711 & 19.51046* & 77.31008 & $3.27 E+03$ & 19.44314 & $20.18647^{*}$ & $19.74501^{*}$ \\
\hline 3 & 38.30523 & $2.28 \mathrm{E}+03$ & 19.07953 & 20.28745 & 19.57007 & 38.77002 & $2.99 \mathrm{E}+03$ & 19.35082 & 20.46582 & 19.80363 \\
\hline 4 & 21.073 & $2.44 \mathrm{E}+03$ & 19.14161 & 20.72119 & 19.78308 & 32.01929 & $2.88 \mathrm{E}+03$ & 19.30961 & 20.79627 & 19.91335 \\
\hline 5 & 32.03285 & $2.32 \mathrm{E}+03$ & 19.08471 & 21.03595 & 19.87712 & 32.61073 & $2.73 E+03$ & 19.25017 & 21.1085 & 20.00485 \\
\hline 6 & 26.26666 & $2.32 E+03$ & 19.07489 & 21.3978 & 20.01823 & 23.16771 & $2.82 \mathrm{E}+03$ & 19.27551 & 21.5055 & 20.18112 \\
\hline 7 & $33.42872 *$ & $2125.388 *$ & 18.9742 & 21.66878 & 20.06848 & $31.39030 *$ & $2655.785^{*}$ & 19.20098 & 21.80263 & 20.25752 \\
\hline 8 & 24.26971 & $2.14 \mathrm{E}+03$ & $18.96191^{*}$ & 22.02815 & 20.20712 & 24.8261 & $2.66 \mathrm{E}+03$ & 19.18553* & 22.15885 & 20.39301 \\
\hline
\end{tabular}

Fonte: Elaboração dos autores

Nota: * denota a ordem de defasagem por critério

LR: sequential modified LR test statistic (each test at $5 \%$ level)

FPE: Final prediction error

AIC: Akaike information criterion

SC: Schwarz information criterion

HQ: Hannan-Quinn information criterion

Quadro 14 - Resultados dos Testes para Ordem do VAR - Oferta de Crédito - Região Centro-Oeste

\begin{tabular}{|c|c|c|c|c|c|c|c|c|c|c|}
\hline \multirow{2}{*}{ Ordem do VAR } & \multicolumn{5}{|c|}{ Com Constante } & \multicolumn{5}{|c|}{ Sem Constante } \\
\hline & LR & FPE & $\mathrm{AIC}$ & SC & $\mathrm{HQ}$ & LR & FPE & $\mathrm{AIC}$ & SC & $\mathrm{HQ}$ \\
\hline 0 & NA & $5.85 E+03$ & 20.02651 & 20.11942 & 20.06424 & - & - & - & - & - \\
\hline 1 & 90.45859 & $3.48 \mathrm{E}+03$ & 19.50658 & $19.97116 *$ & 19.69525 & NA & $4.94 \mathrm{E}+03$ & 19.85661 & $20.22828 *$ & 20.00754 \\
\hline 2 & 47.94721 & $2.95 E+03$ & 19.34129 & 20.17753 & 19.68089* & 49.42467 & $4.15 E+03$ & 19.68198 & 20.42532 & $19.98385^{*}$ \\
\hline 3 & 33.60219 & $2823.749 *$ & $19.29391 *$ & 20.50183 & 19.78445 & 31.65221 & $4.05 E+03$ & 19.65558 & 20.77057 & 20.10838 \\
\hline 4 & 18.06696 & $3.11 E+03$ & 19.38517 & 20.96475 & 20.02665 & 25.36453 & 4.16E+03 & 19.67835 & 21.16501 & 20.28209 \\
\hline 5 & 27.87538 & $3.08 \mathrm{E}+03$ & 19.37027 & 21.32152 & 20.16268 & 35.08666 & $3.85 E+03$ & 19.59415 & 21.45248 & 20.34883 \\
\hline 6 & 22.04967 & $3.22 \mathrm{E}+03$ & 19.40484 & 21.72775 & 20.34818 & 25.70937 & $3.88 \mathrm{E}+03$ & 19.59301 & 21.82301 & 20.49862 \\
\hline 7 & $34.10165 *$ & $2.93 \mathrm{E}+03$ & 19.29676 & 21.99133 & 20.39104 & $34.69129 *$ & $3519.661^{*}$ & 19.48260* & 22.08426 & 20.53915 \\
\hline
\end{tabular}

Fonte: Elaboração dos autores

Nota: * denota a ordem de defasagem por critério

LR: sequential modified LR test statistic (each test at $5 \%$ level)

FPE: Final prediction error

AIC: Akaike information criterion

SC: Schwarz information criterion

HQ: Hannan-Quinn information criterion 
Quadro 15 - Resultados dos Testes para Ordem do VAR - Oferta de Crédito - Região Norte

\begin{tabular}{|c|c|c|c|c|c|c|c|c|c|c|}
\hline \multirow{2}{*}{ Ordem do VAR } & \multicolumn{5}{|c|}{ Com Constante } & \multicolumn{5}{|c|}{ Sem Constante } \\
\hline & $L R$ & FPE & AIC & SC & $\mathrm{HQ}$ & LR & FPE & AIC & SC & $\mathrm{HQ}$ \\
\hline 0 & NA & $6.65 \mathrm{E}+05$ & 24.75947 & 24.85239 & 24.7972 & - & - & - & - & - \\
\hline 1 & 145.1451 & $245902.6^{*}$ & $23.76401 *$ & $24.22859 *$ & $23.95267 *$ & NA & $280438.6^{*}$ & $23.89552 *$ & $24.26719 *$ & $24.04645^{*}$ \\
\hline 2 & 14.65586 & $2.82 E+05$ & 23.89864 & 24.73489 & 24.23824 & 13.77097 & $3.24 \mathrm{E}+05$ & 24.03923 & 24.78256 & 24.3411 \\
\hline 3 & 38.18217 & $2.58 \mathrm{E}+05$ & 23.80846 & 25.01637 & 24.299 & 42.95279 & $2.85 \mathrm{E}+05$ & 23.90819 & 25.02318 & 24.36099 \\
\hline 4 & 15.42092 & $2.91 \mathrm{E}+05$ & 23.92541 & 25.50499 & 24.56688 & 13.99496 & $3.26 \mathrm{E}+05$ & 24.04029 & 25.52695 & 24.64403 \\
\hline 5 & 20.76398 & $3.10 \mathrm{E}+05$ & 23.98234 & 25.93358 & 24.77475 & 23.53973 & $3.39 \mathrm{E}+05$ & 24.07156 & 25.92988 & 24.82623 \\
\hline 6 & 23.51198 & $3.20 \mathrm{E}+05$ & 24.00151 & 26.32442 & 24.94486 & 26.76498* & $3.38 \mathrm{E}+05$ & 24.05942 & 26.28941 & 24.96503 \\
\hline 7 & 16.21136 & $3.54 \mathrm{E}+05$ & 24.09003 & 26.78461 & 25.18431 & 16.27379 & $3.74 \mathrm{E}+05$ & 24.1492 & 26.75086 & 25.20574 \\
\hline 8 & $27.35597^{*}$ & $3.44 \mathrm{E}+05$ & 24.04226 & 27.1085 & 25.28748 & 25.69316 & $3.71 E+05$ & 24.1239 & 27.09722 & 25.33138 \\
\hline
\end{tabular}

Fonte: Elaboração dos autores

Nota: * denota a ordem de defasagem por critério

LR: sequential modified LR test statistic (each test at $5 \%$ level)

FPE: Final prediction error

AIC: Akaike information criterion

SC: Schwarz information criterion

HQ: Hannan-Quinn information criterion

Figura 1 - Teste de Estabilidade (AR Roots)

Comportamento dos Bancos - Região Sudeste

Inverse Roots of AR Characteristic Polynomial

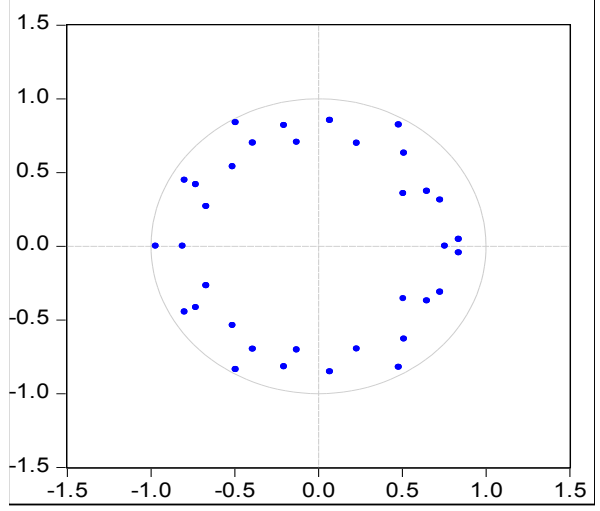

Fonte: Elaboração dos autores

Figura 2 - Teste de Estabilidade (AR Roots)

Comportamento dos Bancos - Região Nordeste

Inverse Roots of AR Characteristic Polynomial

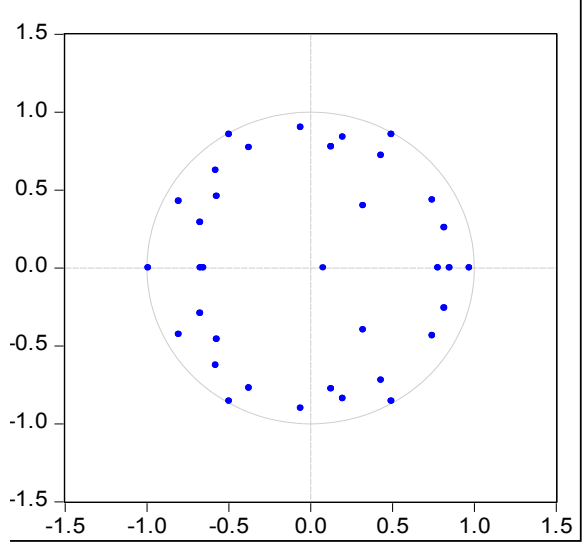

Fonte: Elaboração dos autores
Figura 3 - Teste de Estabilidade (AR Roots)

Comportamento dos Bancos - Região Sul

Inverse Roots of AR Characteristic Polynomial

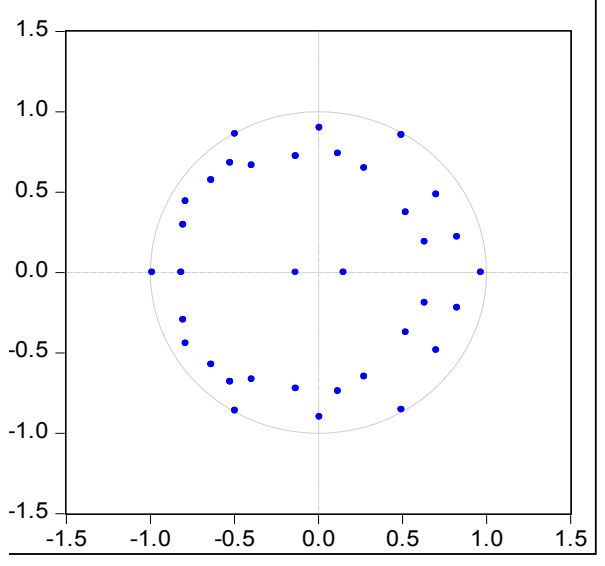

Fonte: Elaboração dos autores

Figura 4 - Teste de Estabilidade (AR Roots)

Comportamento dos Bancos - Região Centro-Oeste

Inverse Roots of AR Characteristic Polynomial

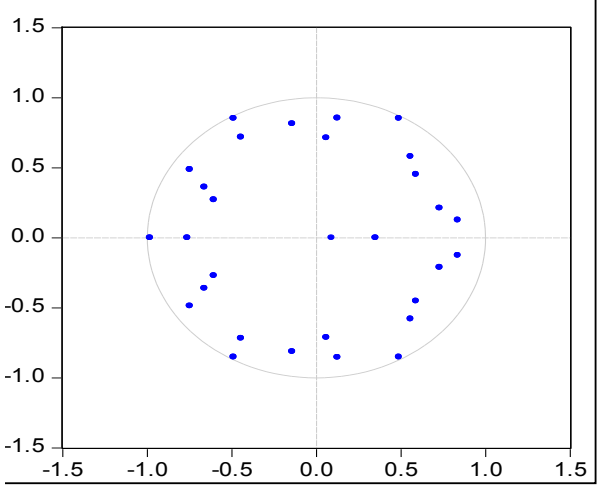

Fonte: Elaboração dos autores 
Figura 5 - Teste de Estabilidade (AR Roots) Comportamento dos Bancos - Região Norte

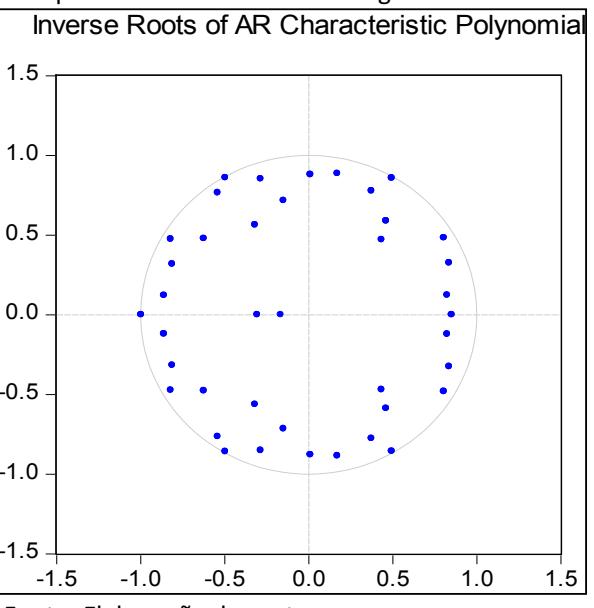

Fonte: Elaboração dos autores

Figura 6 - Teste de Estabilidade (AR Roots) Oferta de Crédito - Região Sudeste

Inverse Roots of AR Characteristic Polynomia

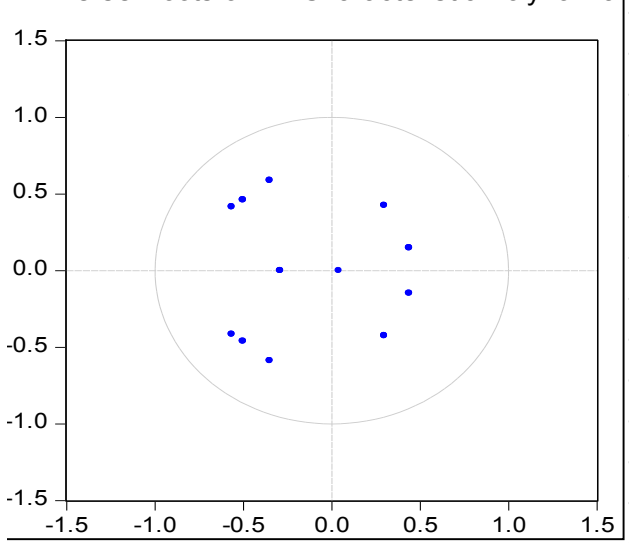

Fonte: Elaboração dos autores

Figura 7 - Teste de Estabilidade (AR Roots)

Oferta de Crédito - Região Nordeste

Inverse Roots of AR Characteristic Polynomial

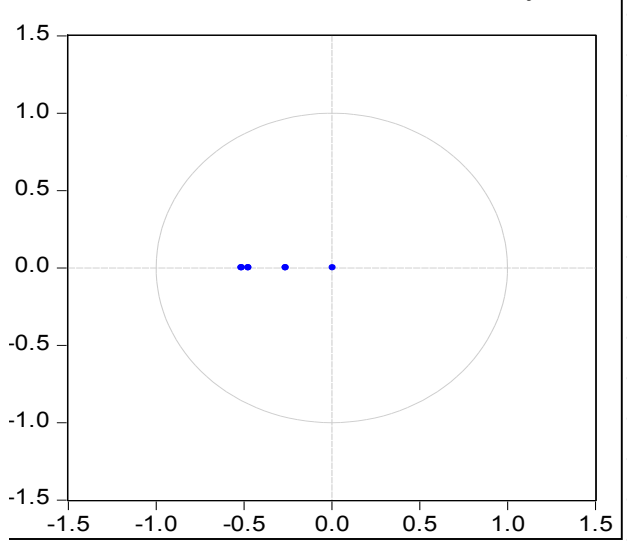

Fonte: Elaboração dos autores
Figura 8 - Teste de Estabilidade (AR Roots)

Oferta de Crédito - Região Sul

Inverse Roots of AR Characteristic Polynomia

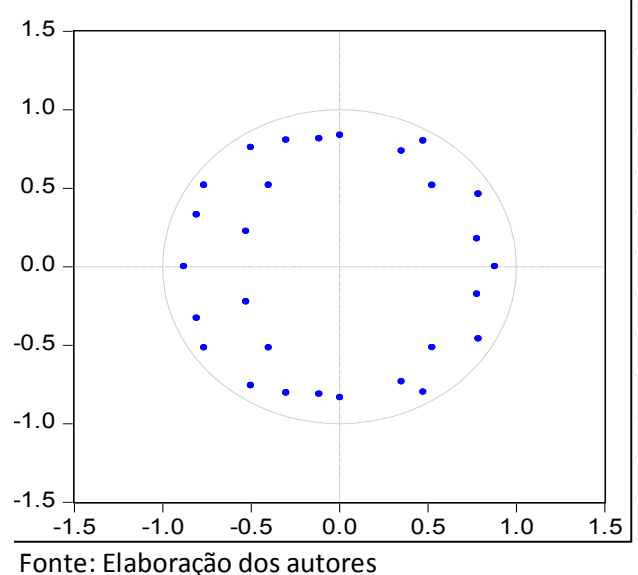

Fonte: Elaboração dos autores

Figura 9 - Teste de Estabilidade (AR Roots)

Oferta de Crédito - Região Centro-Oeste

Inverse Roots of AR Characteristic Polynomial

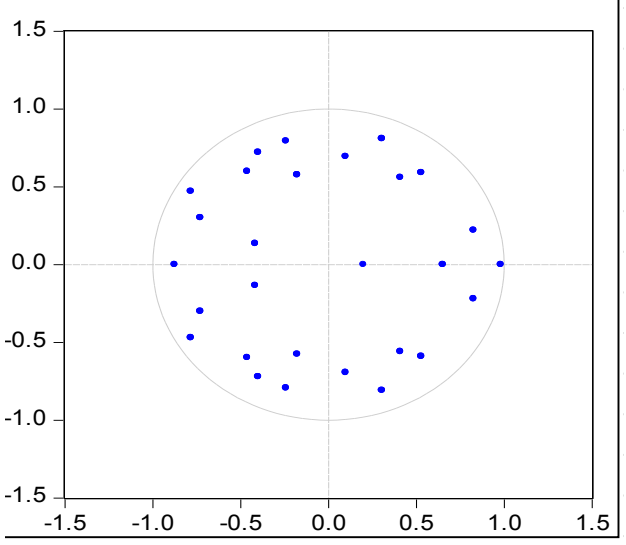

Fonte: Elaboração dos autores

Figura 10 - Teste de Estabilidade (AR Roots)

Oferta de Crédito - Região Norte

Inverse Roots of AR Characteristic Polynomial

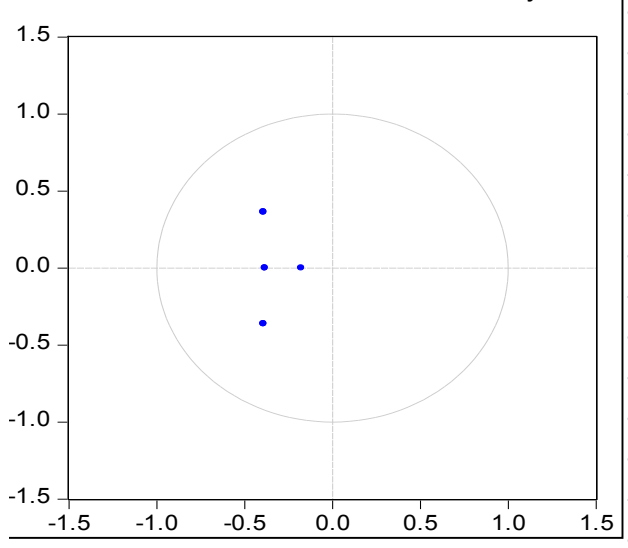

Fonte: Elaboração dos autores 